\title{
1 Measurements and Simulations of Aerosol 2 Released while Singing and Playing Wind 3 Instruments
}

4 Tehya Stockman $^{\mathrm{a}^{*}}$, Shengwei Zhu ${ }^{\mathrm{b}}$, Abhishek Kumar ${ }^{\mathrm{c}}$, Lingzhe Wang ${ }^{\mathrm{d}}$, Sameer Patel ${ }^{\mathrm{e}}$, James Weaver , 5 Mark Spede $^{\mathrm{g}}$, Don Milton ${ }^{\mathrm{h}}$, Jean Hertzberg ${ }^{\mathrm{i}}$, Darin Toohey ${ }^{\mathrm{j}}$, Marina Vance ${ }^{\mathrm{k}}$, Jelena Srebric ${ }^{1}$, Shelly L.

6 Miller $^{\mathrm{m}^{*}}$

${ }^{a}$ Department of Civil, Environmental, and Architectural Engineering, University of Colorado Boulder,

9 Boulder, CO, 80309, USA

$10{ }^{\mathrm{b}}$ Department of Mechanical Engineering, University of Maryland, College Park, 20742, MD, USA

$11{ }^{\mathrm{c}}$ Department of Mechanical Engineering, University of Colorado Boulder, Boulder, 80309, CO, USA

$12{ }^{\mathrm{d}}$ Department of Mechanical Engineering, University of Maryland, College Park, 20742, MD, USA

$13{ }^{\mathrm{e}}$ Department of Civil Engineering, Indian Institute of Technology, Gandhinagar, Gujrat, 382355, India

$14{ }^{\mathrm{f}}$ National Federation of State High School Associations, Indianapolis, IN, 46402, USA

15 g Department of Performing Arts, Clemson University, Clemson, SC, 29634, USA

$16{ }^{\mathrm{h}}$ Maryland Institute for Applied Environmental Health, School of Public Health, University of Maryland,

17 College Park, MD, 20740, USA

$18{ }^{\mathrm{i}}$ Department of Mechanical Engineering, University of Colorado Boulder, Boulder, 80309, CO, USA

$19 \mathrm{j}^{\mathrm{j}}$ Department of Atmospheric and Oceanic Sciences, University of Colorado Boulder, Boulder, 80309, 20 CO, USA

$21{ }^{\mathrm{k}}$ Department of Mechanical Engineering, University of Colorado Boulder, Boulder, 80309, CO, USA

$22{ }^{1}$ Department of Mechanical Engineering, University of Maryland, College Park, 20742, MD, USA

$23{ }^{\mathrm{m}}$ Department of Mechanical Engineering, University of Colorado Boulder, Boulder, 80309, CO, USA

$24 *$ Corresponding authors emails: Tehya.Stockman@colorado.edu, Shelly.Miller@colorado.edu

\section{Abstract}

29 Outbreaks from choir performances, such as the Skagit Valley Choir, showed that singing brings potential risk of COVID-19 infection. There is less known about the risks of airborne infection from other musical performance, such as playing wind instruments or performing theatre. In addition, it is important to 
including flow visualization, aerosol and $\mathrm{CO}_{2}$ measurements, and computational fluid dynamics (CFD) modeling to understand the different components that can lead to transmission risk from musical performance and risk mitigation. This study was possible because of a partnership across academic departments and institutions and collaboration with the National Federation of State High School Associations and the College Band Directors National Association. The interdisciplinary team enabled us to understand the various aspects of aerosol transmission risk from musical performance, and quickly implement strategies in music classrooms during the COVID-19 pandemic. We found that plumes from musical performance were highly directional, unsteady, and vary considerably in time and space. Aerosol number concentration measured at the bell of the clarinet were comparable to singing. Face and bell masks attenuated plume velocities and lengths and decreased aerosol concentrations measured in front of the masks. CFD modeling showed differences between indoor and outdoor environments and that lowest risk of airborne COVID-19 infection occurred at less than 30 minutes of exposure indoors and less than

Keywords: Aerosol transmission, Aerosol concentration, Aerosol size distribution, Wind instruments, Singing, Theatre, Computational fluid dynamics, Flow visualization, Schlieren imaging, Laser sheet imaging

The significance of infectious disease transmission by inhalation of airborne respiratory particles (also commonly referred to as 'aerosol') has been intensely discussed in the context of the coronavirus disease (COVID-19) worldwide pandemic, caused by the severe acute respiratory syndrome coronavirus 2 (SARS-CoV-2), ${ }^{1}$ and there is strong empirical evidence for airborne transmission of SARS-CoV-2. Several studies have detected and/or cultured SARS-CoV-2 in air samples and found virus on the surfaces of ventilation exhaust vents. ${ }^{2-9}$ SARS-CoV-2 virus has also been reported detected in exhaled breath of infected individuals ${ }^{10}$ and has been shown to transmit disease via aerosol inhalation in animal. ${ }^{11}$ Outbreak investigations reported transmission by aerosol to be the most plausible explanation of a large number of exposed individuals not located directly near the index case. ${ }^{1,12}$

Because of this risk of infection via inhalation of aerosol, many activities that occurred prior to the pandemic have been modified, especially those that have the potential to generate respiratory airborne particles. These activities include singing, performing theatre, and playing band instruments. Singing has been implicated in several outbreaks. ${ }^{12,13}$ There have been no reports yet implicating the playing of 66 instruments, but there have been reports of musicians spreading virus in a bar outbreak in Hong Kong. ${ }^{14}$ 
However, the potential for wind instrument spread is likely. In one study, the number of particles emitted while playing plastic blowing horns called vuvuzelas (used by sports fans) was 658 particles $\mathrm{cm}^{-3}$ compared to 3.7 particles $\mathrm{cm}^{-3}$ for shouting. The majority of these particles were between 0.5 and 5 microns in diameter. ${ }^{15}$ Loudon and Roberts (1968) reported that, for singing, the count median diameter was $68 \mu \mathrm{m}$ with a geometric standard deviation of $3.3 ; 34 \%$ of the particles were smaller than $3 \mu \mathrm{m}$, and $33 \%$ were between 3 and $114 \mu \mathrm{m} .{ }^{16}$ After a 30 -min settling period, $36 \%$ of the emitted droplets were still airborne. Asadi et al. (2019) showed that the rate of aerosol emission during vocal activities increases with the loudness of the sound. ${ }^{17}$ Measurements of aerosol number concentrations released during sustained vocalization were shown to be comparable to voluntary coughing and higher than speaking. ${ }^{18}$ Alsved et al. (2020) conducted a study of 12 singers utilizing an APS and a high-speed camera found that singing produced more aerosol compared to normal talking and breathing, and that singing or talking louder also generated more aerosol. ${ }^{19} \mathrm{He}$ et al. (2021) recently conducted a study of various musical instruments and found that aerosol generation can vary substantially across musical instruments and can be affected by dynamic level, articulation, and individual performers. ${ }^{20}$

The singing outbreaks and the published data on plastic horn playing suggest that further investigation is warranted into the possibility of infectious aerosol generated from playing wind instruments. Concern has been expressed specifically regarding woodwind and brass instruments because the sound is produced by a controlled flow of exhaled air. The objective of this study was to better understand aerosol production in wind instrument playing, singing, and acting so that musicians, performers, and students of music could resume playing in rehearsal and public spaces in a safer manner for the nearby musicians and audience during the COVID-19 pandemic. We approached this problem by using fluid flow visualization techniques to first understand the respiratory flow patterns from these activities. Based on these results, we measured the aerosol and $\mathrm{CO}_{2}$ produced in the major flow fields while performing. We also modeled the aerosol production using computational fluid dynamics (CFD) to predict risk of infection. Finally, mitigation strategies were developed and investigated through modeling and measurements.

\section{Methods}

Research teams at the University of Colorado Boulder and at the University of Maryland worked collaboratively and in parallel on different aspects of the project. The CU Boulder team conducted flow visualization and aerosol experiments and the University of Maryland also conducted aerosol experiments and CFD modeling. 


\subsection{Scripted activities and study subjects}

Activities performed for this study incorporated instrument playing as well as vocal performances, including five woodwind instruments (three flute, two clarinet, one oboe, one saxophone, and one bassoon player), four brass instruments (one French horn, one trumpet, one trombone, and one tuba), two vocal ranges (one female soprano, one male baritone), and one theatre performer.

Each wind instrument player was asked to perform the same piece of music four times in a row, totaling four to five minutes of almost continuous playing with short rest breaks in between. The piece of music was "Holt in E-flat for COVID-19 Study," which was selected specifically for this study and consisted of a slurred chromatic scale encompassing each instrument's normal range, and "Holt in Eb." The singers were asked to perform a warm-up, a hymn piece, and a musical theatre piece. The theatre performer was asked to recite two monologues from memory. All participants were asked to read a standard text used in speech pathology practice called "The Caterpillar," which is a simple reading designed for a wide range of ages that contains a variety of consonants and vowels of English speech. ${ }^{21}$

\section{Data collection occurred during summer and fall 2020 and subjects were recruited for their ability to play} an instrument, sing, or perform, proximity to campus during the data collection period, and availability. Musicians in this study were upper-level undergraduate or graduate students aged 20-30 y old studying music at the University of Colorado Boulder. The theatre performer was a male professor and was $>30 \mathrm{y}$ old. Participants filled out a health questionnaire before coming to the lab. No participants showed symptoms of sickness during the course of the experiments. This study was reviewed and approved by the Institutional Review Board at the University of Colorado at Boulder (Protocol \#20-0281).

\subsection{Aerosol testing room}

Flow characterization and exhaled aerosol plume measurements were conducted in a $37.8 \mathrm{~m}^{3}(3.1 \mathrm{~m} \times 3.7$ $\mathrm{m} \times 3.3 \mathrm{~m}$ with a pillar-like structure on one of the walls) aerosol testing room at the University of Colorado Boulder. This room has no supply ventilation but a dedicated ventilation exhaust, with a ventilation damper that can be opened or closed on demand by the room operator, from outside of it. When the exhaust damper is opened, the slight vacuum caused by this exhaust system results in laboratory air being pulled into the testing room and the air within the test room being exhausted outdoors. This exhaust system was operated in between experiments to remove any emitted aerosol from the room. During experiments, the test room was operated with the exhaust damper closed and at a slight positive pressure $(\sim 2 \mathrm{~Pa})$. Blue painter's tape was used to limit infiltration through the cracks around the 
133 test room door. Figure 1 shows the position of instrumentation during flow characterization and aerosol

134 plume measurements.

135

$$
\text { light }_{\text {ligure }}^{\text {Camera }}
$$

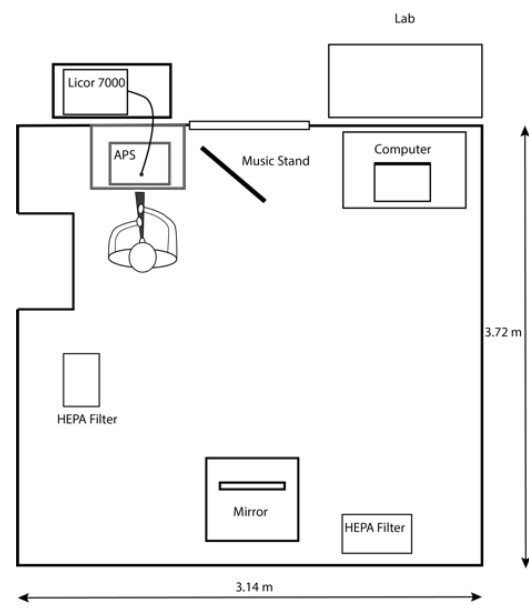

(a)

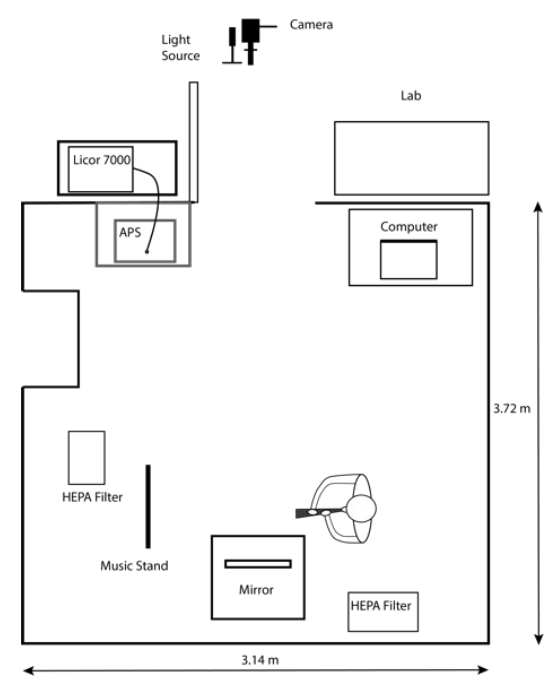

(b)

138 Figure 1. Top-down schematic view of test room set up for aerosol measurements (a) and flow characterization through schlieren imaging (b). Not drawn to scale. The test room has a glass window, allowing a researcher to monitor activities performed by subjects indoors. The door was kept open during flow characterization experiments to accommodate the light source and camera setup.

142 This test room is not a certified clean room and has a changing background concentration of particles over

143 time, likely due to infiltration through the exhaust damper. To reduce background particle concentrations

144 to the lowest possible level for these experiments, two portable air cleaners outfitted with HEPA filters

145 (Air Response Air Purifier, Oreck), supplying a total effective particulate air exchange rate of $15 \mathrm{~h}^{-1}$, were

146 run to decrease the background levels of airborne particles between test runs. Background measurements

147 were also performed for each participant in which the participant turned the HEPA filters off and sat

148 within the test room, without performing any activities, for $\sim 4$ minutes. The total particle number

149 background concentration in the chamber reported by the APS was $0.03-0.1 \# / \mathrm{cm}^{3}$.

151 During experiments, a researcher stood outside the testing room to monitor the participant through a

152 window in the chamber door. Participants were asked to not leave the testing room after the start of the experiment. The researcher communicated with the participant over video call while the participant was

154 in the testing room to relay information to the participant about what to do. The floor and other surfaces of the testing chamber were cleaned with soap and water before and after each experiment.

157 A $0.58 \times 0.41 \times 0.31 \mathrm{~m}(53 \mathrm{~L})$ polypropylene box was used to measure aerosol emissions directly from 158 the bell of select musical instruments. The interior surfaces were lined with aluminum foil and grounded 
to minimize electrostatic losses. This box was operated inside the aerosol test room and sampling inlets to

160 all aerosol and gas-phase instruments were moved to this box during its use. HEPA filtered air was

161 supplied to the box at $16 \mathrm{~L} \mathrm{~min}^{-1}$ to maintain a slight positive pressure of $\sim 1 \mathrm{~Pa}$.

\subsection{Mitigation Strategies}

164 During aerosol measurements, we evaluated three mitigation strategies, specific to the type of performer:

165 (1) surgical mask wearing by the singer and theatre performer, (2) a surgical mask placed directly over the 166 bell of woodwind instruments, and (3) a cover made of MERV-13 filter material inside of a spandex

167 layer, placed over the bell of the brass instruments. Using CFD modeling, we also estimated the effects of 168 different ventilation strategies, length of performance time, and indoors versus outdoors location.

\subsection{Flow Characterization}

171 Prior to aerosol measurements, the subject came into the lab for flow visualization of their musical or 172 vocal performance. The flow visualization was used to determine where the air flow escapes the 173 instrument or mouth of each performer, the velocities of these plumes, and the length and width of the 174 plumes. An aerosol plume was defined as located where the highest temperature/velocity flow field was 175 identified and where the aerosol concentrations were highest. Flow visualization information guided 176 researchers on where to position each participant (and their instrument) to collect aerosol and $\mathrm{CO}_{2}$ 177 measurements from the plumes. Flow visualization experiments were performed through schlieren 178 technique and laser sheet imaging, while velocity measurements were made by a hot wire anemometer 179 (405i, Testo Inc., Lenzkirch, Germany). Flow videos were recorded at high speed (120 fps, at $1080 \mathrm{p}$ 180 resolution) and at regular speed (30 fps, at $4 \mathrm{~K}$ resolution) using two cameras (EOS 90D and EOS T3i, 181 Canon, Tokyo, Japan) with a $300 \mathrm{~mm}$ focal length lens. The images were also analyzed quantitatively to

182 calculate flow velocities. Velocity data was subsequently used for boundary conditions in CFD 183 simulations.

\subsubsection{Schlieren Imaging}

186 The schlieren system used in this study consisted of a single mirror system as shown in Figure 2. The 187 mirror was parabolic with a focal length of $2.44 \mathrm{~m}$ and a diameter of $0.3048 \mathrm{~m}$. The light source was a 188 MiniMag LED flashlight with lens removed. The schlieren stop was a vertical razor edge. Estimates of jet 189 velocity were made from the schlieren videos by manual frame-to-frame tracking of jet features. There 190 are some limitations to schlieren imaging, e.g., it is difficult to differentiate between the air currents 
192 the body.

193

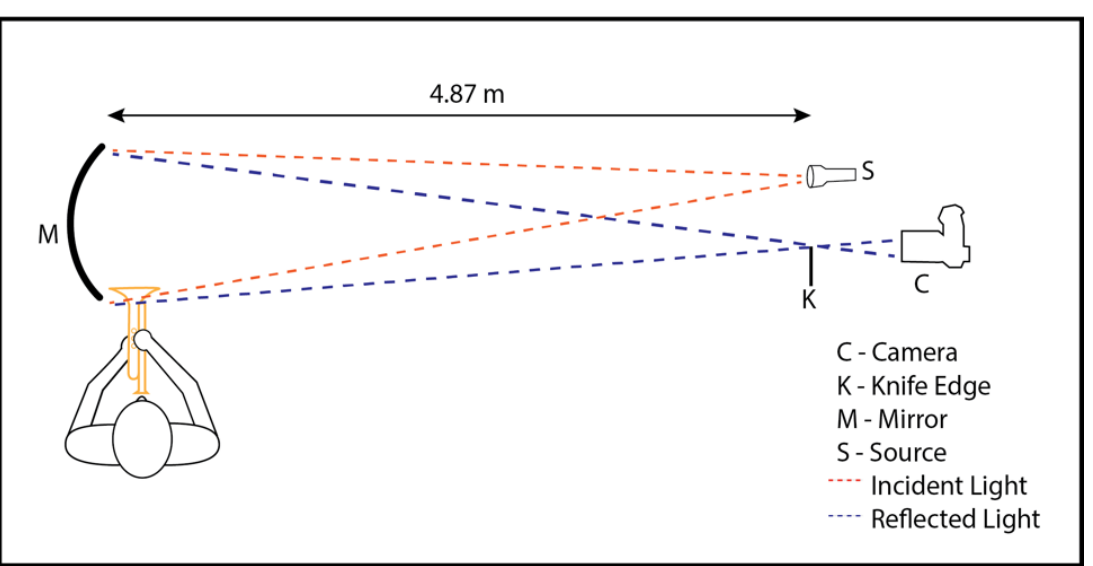

Figure 2. Top-down schematic of the schlieren setup.

Participants stood in front of the mirror and were asked to play the chromatic scale in whole notes with various locations of their instruments in view of the mirror: the bell, mouthpiece, and keys of the instruments. Musicians playing instruments were asked to tongue each note so that there would be adequate separation between the notes and each note was recorded on video. The participant and researcher identified notes that produced exceptionally large or fast plumes.

\subsubsection{Laser sheet imaging}

For laser sheet imaging, the test room was filled with stage fog and circulated throughout the room. A 0.8-W blue continuous wave diode laser (assembled in house) was formed into a sheet by a $12.7 \mathrm{~mm}$ cylindrical lens to illuminate the fog. Although subjects inhaled the fog, their exhalations through the musical instruments were free of fog and showed as dark regions in images of the laser sheet. The same cameras as above were used to record images and videos, using a 24-105 $\mathrm{mm}$ lens. The laser sheet was alternately oriented perpendicular (front view) and parallel (side view) to the axis of each instrument's bell. For cross-sectional images of the plume, the bell was typically 50 to $100 \mathrm{~mm}$ from the vertical sheet. To measure plume extent, the participant was positioned in the laser sheet. They were given opaque eye masks and swathed in black velvet, excepting only the opening a few inches into the bell, as shown in Figure 3. This both protected the participant and minimized stray reflections of the laser. However, draping the performer does disrupt the buoyant plume that normally surrounds the human body. At the same time, instruments are generally played while angled away from the body, minimizing the interaction of the instrument's exhalation jets with the body's thermal plume. Thus, the loss of the plume in the laser sheet imaging was deemed acceptable. In both orientations, movement of the musician while playing 
218 due to safety precautions. Subjects were asked to play the chromatic scale and a musical piece from

219 memory. Spatial calibration images were also acquired for each setup.

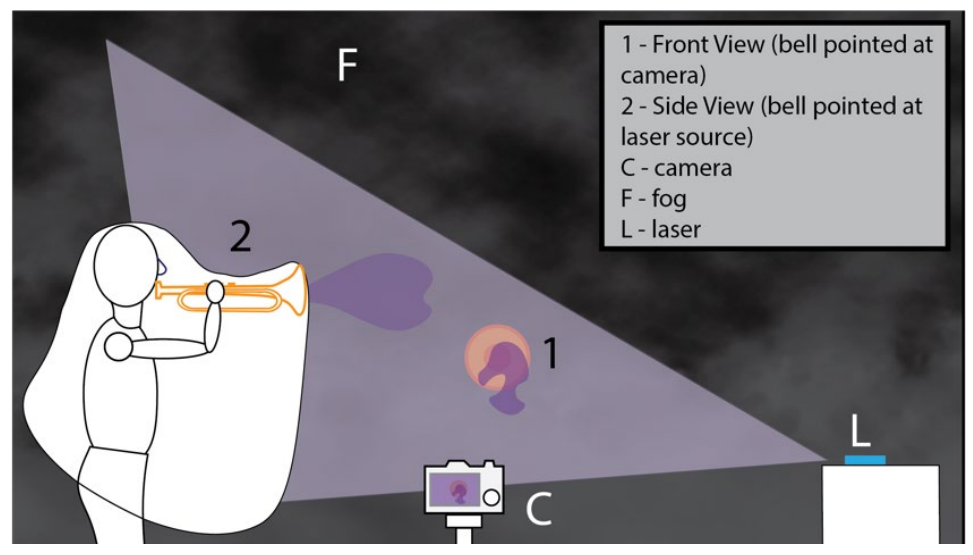

(a)

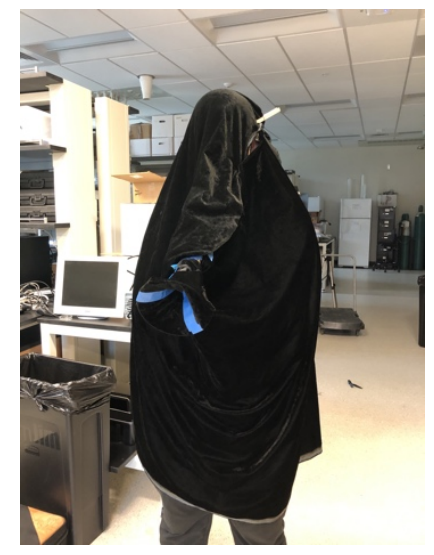

(b)

Figure 3. Laser sheet imaging: (a) schematic figure describing the experimental setup and (b) photo of the trumpet player prepared for imaging. The blue tape identifies the trumpet bell.

\subsubsection{Velocities from Image Analysis}

The schlieren and laser sheet videos were subject to video analysis. At the beginning of a note the leading edge of the plume was manually tracked frame to frame for one second, from the bell of the instrument or mouth of the singer. Distance over time provided velocity. Distances were calibrated from frames showing a known scale, typically a US letter $(216 \times 279 \mathrm{~mm})$ sheet of paper. The uncertainty for the schlieren velocities was $\pm 15 \%$ and $\pm 10 \%$ for the laser sheet values. These estimates account for motion of the bell during performance and the ability to accurately identify the edge of the plume front.

\subsubsection{Anemometer measurements}

A hot wire anemometer was also used to measure the peak velocity of the principal flows in multiple locations for each musical instrument (e.g., bell, fipple, keys etc.) during notes that were identified through the schlieren imaging to be especially fast or have a large extent coming from the bell. The subject played an extended note, and the researcher moved the anemometer probe around the bell and recorded the highest velocity measurement while the participant exhaled. Uncertainty was estimated at $20 \%$, or $0.10 \mathrm{~m} / \mathrm{s}$, primarily due to the variability of positioning.

\subsection{Aerosol and gas-phase plume-level measurements}

An aerodynamic particle sizer (APS 3321, TSI), Licor (LI-7000, Li-Cor, Lincoln, NE), and an ultra high sensitivity aerosol spectrometer UHSAS (UHSAS, Droplet Measurement Technologies, Boulder, CO) 
were used for plume-level measurements in the chamber. Total particle concentrations $(\sim 0.5-10 \mu \mathrm{m})$ and

244 particle size distributions $(\sim 0.5-20 \mu \mathrm{m})$ were monitored using the aerodynamic particle sizer (APS). The

245 APS was placed inside the test room using a $0.15-\mathrm{m}$ straight conductive silicone inlet (3.18 $\mathrm{mm}$ inner

246 diameter) sampling at $1 \mathrm{~L} \mathrm{~min}^{-1}$ to minimize particle losses. The APS measured one particle size

247 distribution every minute. A limitation to using the APS is the ability to measure liquid particles close to

248 or greater than $10 \mu \mathrm{m}$ in diameter. Volckens and Peters (2005) found that efficiencies of liquid droplets

249 progressively decreased from $75 \%$ for liquid droplets of $8 \mu \mathrm{m}$ to $25 \%$ for $10 \mu \mathrm{m}$ droplets. ${ }^{22}$

Particle size distribution ( 200nm -1000nm) was monitored using the UHSAS, which was placed outside of the test room using a 1-m conductive silicone inlet (3.18 $\mathrm{mm}$ inner diameter). The overlapping size ranges of the UHSAS and APS were checked against each other.

Carbon dioxide $\left(\mathrm{CO}_{2}\right)$ was used as a marker for respiratory activity, measured using the $\mathrm{CO}_{2} / \mathrm{H}_{2} \mathrm{O}$ nonair from the UHSAS fed into the Licor. The Licor and UHSAS were placed outside the chamber to minimize noise, heat load, and particle emissions from associated pumps and sampled through a conductive silicone inlet ( $1 \mathrm{~m}$ length, $3.18 \mathrm{~mm}$ inner diameter), fed through a sampling port in the wall next to the APS inlet. The inlets for the Licor/UHSAS and APS were placed next to each other. Inlets were positioned based on flow visualizations results but also in part to accommodate the height of each musician, approximately $15-20 \mathrm{~cm}$ from the bell of the instrument or the mouth of the performer. For some musical instruments, the APS was placed on its side to minimize particle losses by avoiding bends in the inlet tube.

The Licor and UHSAS sampled $\mathrm{CO}_{2}$ and particle size distribution once per second. The Licor and UHSAS data were averaged to every minute. Aerosol measurements and $\mathrm{CO}_{2}$ were also averaged over the duration of each test from some of the analyses, and averaging times were usually around 4 minutes. The background particle concentration recorded during each experiment was subtracted from all of the data.

272 The clarinet was played into the small polypropylene box. Particle size distributions and $\mathrm{CO}_{2}$

273 concentrations were measured using the APS, UHSAS and Licor with sampling ports on the backside of 274 the box. The supply air to the box had 0 particles $\mathrm{cm}^{-3}$ particles and $0 \mathrm{ppm} \mathrm{CO}_{2}$. The background 275 concentration inside the box was approximately 0 particles $\mathrm{cm}^{-3}$ prior to each test. The same note, a "C" 276 on the clarinet, was played for 4 minutes with and without a bell mask. A middle " $\mathrm{C}$ " on the clarinet 
277 (concert $\mathrm{Bb}$ ) has one keyhole open near the bell of the clarinet when played. The three different tests

278 performed in the box were: playing with no bell mask, playing with bell mask with the uncovered keyhole

279 in the box, and playing with bell mask with the uncovered keyhole outside of the box. These experiments

280 were done to better understand emissions from the keyholes of the clarinet. The box was assumed to

281 become well-mixed rapidly, so sampling was not done in the aerosol plume from the instrument's bell,

282 but rather from the mixed air in the box.

\subsection{CFD modeling of singing and clarinet playing rehearsals}

285 Computational fluid dynamics was used to simulate the spread of SARS-CoV-2 viruses from the mouth

286 of a singer and the bell of a clarinet while performing indoors and outdoors. Based on the concept of

287 infectious quanta, ${ }^{23}$ CFD simulations used a passive scalar to represent the viral aerosol, and then

288 implemented the Well-Riley equation ${ }^{24}$ to estimate the infection risk of COVID-19. Quanta represent an

289 infectious dose of respiratory aerosol when the viral dose to cause infection in people is unknown. ${ }^{12}$ The

290 measured data from the aerosol emission experiments served as inputs into the CFD simulations as

291 boundary conditions. This approach characterized the risk to musicians of potential airborne infection

292 transmission under realistic music rehearsal scenarios.

294 2.7.1 Modeling of indoor environment

295 CFD modeling for a rehearsal room is shown in ${ }^{24}$ (a) and (b). The information on indoor climate was 296 provided by the facilities management about the University of Colorado Boulder rehearsal rooms. Virus297 free air was supplied from the inlets at a spreading angle of $30^{\circ}$ downward. The singer or clarinet player 298 stood under the air supply diffuser, with a convective heat loss of $33.8 \mathrm{~W}$ from skin surface. For singing, 299 air of $32^{\circ} \mathrm{C}^{25}$ was exhaled at a speed of $0.56 \mathrm{~m} / \mathrm{s} .{ }^{26}$ Based on measurements with a clarinet player in the 300 aerosol testing room, the clarinet's bell with a $6-\mathrm{cm}$ diameter had air of $23.7^{\circ} \mathrm{C}$ coming out at a speed of $3010.9 \mathrm{~m} / \mathrm{s}$, which is characteristic of an initial jet from the clarinet leading to a conservative estimate of risk. 302 Moreover, the clarinet was positioned at $45^{\circ}$ downward to represent a typical instrument position. The 303 detailed CFD boundary conditions are listed in Table 1. We used the fine grid systems with around 1.654 $304 \mathrm{M}$ and 1.8 M spatial cells in Case 1 and 2, respectively, and around 55,000 triangle meshes to capture the 305 curved features of human body surfaces. As a result, the grid quality was ensured with aspect ratio under 3068 , and skewness equi-angle under 0.8 . 


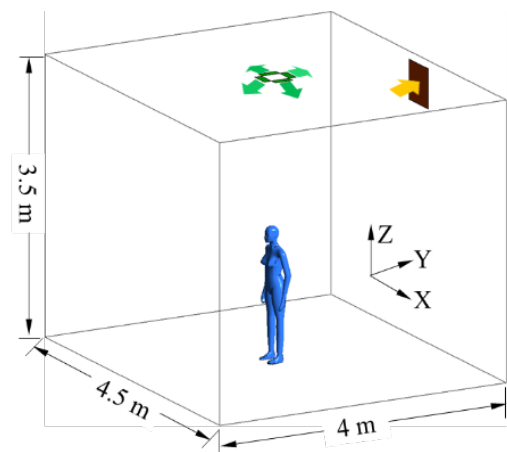

(a) Case 1 with a singer indoors

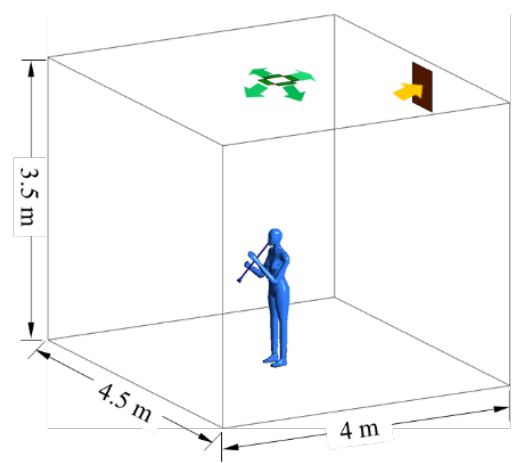

(b) Case 2 with a clarinet player indoors

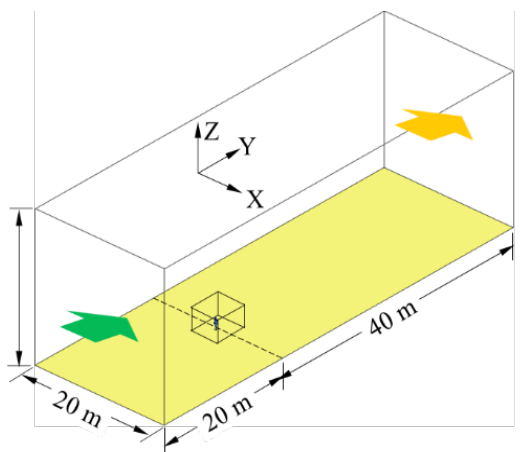

(c) Case 3 with a singer and 4 with a clarinet player outdoors

Figure 4. Simulation domains for CFD modeling of indoor and outdoor music performances.

\section{$310 \quad$ 2.7.2 Modeling of outdoor environment}

311 Figure 4 (c) gives the CFD modeling for the singing and clarinet playing cases outdoors. The surface

312 meshes, geometry, and boundary conditions for the musician body and clarinet were the same as those

313 used in the indoor cases. The singer/clarinet player was located in the middle of the ground plain and 20

314 m away from the inlet. At the inlet, the logarithmic wind profile $U(z)$, the turbulence specification

315 method, including turbulent kinetic energy $(\kappa)$, and the turbulent dissipation rates $(\varepsilon)$, and the temperature

$316 T$ were given as follows: ${ }^{27-30}$

$317 \quad \frac{U(Z)}{u^{*}}=\frac{1}{k} \ln \frac{z+z_{0}}{z_{0}} ; \kappa=\frac{u^{* 2}}{0.3} ; \quad \varepsilon=\frac{u^{* 3}}{\kappa\left(z+z_{0}\right)} ; T=22.2-0.02 * Z$

318 where $k$ is the von Karman constant $(=0.41), u^{*}$ is the friction velocity, and $z_{0}$ is the roughness length $(=$

$3190.003 \mathrm{~m})$. The velocity at the height of $10 \mathrm{~m}\left(U_{10}\right)$ is the bulk velocity, which was $1 \mathrm{~m} / \mathrm{s}$. The details of

320 other boundary conditions are given in Table 1 . To save computational time, a small box of X6 m $\times$ Y $6 \mathrm{~m}$

$321 \times \mathrm{Z} 3 \mathrm{~m}$ was created with the human body (with clarinet) standing at its center. We created the fine grid

322 systems in the small box with around 2.64 M and 2.69 M spatial cells in Case 3 and 4, respectively. As a

323 result, the quality of meshes in the small box was ensured with aspect ratio under 7.2, and skewness equi-

324 angle under 0.82 . A structured grid was employed for the space outside of the small box with a total

325 number of 904,000 meshes.

326

327 Table 1. Boundary conditions for indoor/outdoor domains and the musician body

\begin{tabular}{l|l}
\hline Indoor air inlets & $\begin{array}{l}\text { Size: } 0.25 \mathrm{~m} \times 0.1 \mathrm{~m}(4) ; \text { Ventilation rate: } 3 \mathrm{ACH} ; \text { Velocity inlet; } V: 0.909 \mathrm{~m} / \mathrm{s} \text { at } \pm \mathrm{x} \\
\text { or } \pm \mathrm{y} \text { direction, and } 0.525 \mathrm{~m} / \mathrm{s} \text { at }-\mathrm{z} \text { direction; } T: 22^{\circ} \mathrm{C},\end{array}$ \\
\hline Outdoor air inlet & As given in Eq. $(1) \sim(4)$ \\
\hline Air outlets & Outflow; Free slip \\
\hline
\end{tabular}




\begin{tabular}{l|l}
\hline Mouth opening & Area: $3.8 \mathrm{~cm}^{2} ;$ Velocity inlet; $V: 0.56 \mathrm{~m} / \mathrm{s} ; T: 32^{\circ} \mathrm{C}$ \\
\hline Body surface & Area: $1.47 \mathrm{~m}^{2} ;$ Convective heat transfer: $33.8 \mathrm{~W}$ \\
\hline Room walls & Adiabatic wall; No slip \\
\hline Bell opening & $d: 6 \mathrm{~cm} ;$ Velocity inlet; $V: 0.9 \mathrm{~m} / \mathrm{s} ; T: 23.7^{\circ} \mathrm{C}$ \\
\hline Sides and sky & Symmetry \\
\hline Other wall surfaces & Adiabatic wall; No slip \\
\hline
\end{tabular}

2.7.3 CFD numerical methods and COVID-19 risk assessment

330 The CFD simulation used the Renormalization Group (RNG) $\kappa-\varepsilon$ turbulent model, ${ }^{31}$ which solved the

331 governing equations of mass conversation, momentum, energy, $\kappa$ and $\varepsilon$ using the finite volume method. ${ }^{32}$

332 The Boussinesq assumption was applied considering buoyancy forces on the warm free convective

333 airflow around the musician body. The PRESTO algorithm for pressure-velocity coupling was used, with

334 the second-order upwind spatial discretization for other variables. The above CFD methods have been

335 validated with the comparison to the experimental data of velocity, air temperature, and contaminant

336 concentration distributions..$^{33}$ The convergence criterion was $1 \times 10^{-6}$ for energy, and $4 \times 10^{-4}$ for the

337 indoor cases and $1 \times 10^{-4}$ for the outdoor cases for other variables.

339 The viral aerosol was expressed with infectious quanta (Wells, 1955) and represented by a passive

340 scalar. ${ }^{23}$ For such small particles, evaporation would be completed in $0.03 \mathrm{~s}$ with little influence from the

341 environmental humidity and temperature, ${ }^{34}$ moreover, this small-sized bioaerosol is carried and spread by

342 air currents. ${ }^{25}$ Quanta generation rate was set to be 48 quanta/h. ${ }^{35}$ The convergence was satisfied with the

343 residual reduced to under $1 \times 10^{-6}$. We calculated using Eq. 2 the probability of aerosol COVID-19

344 infection, $P$, by applying the Wells-Riley equation ${ }^{24}$ with the CFD calculated quantum concentration

345 distribution in the horizontal section at the height of mouth.

$346 P=1-e^{-p N t}$

347 where $P$ is the infection probability; $p$ is the breathing rate $(=8 \mathrm{~L} / \mathrm{min}) ; N$ is the concentration of quanta

$348\left(\right.$ quanta $\left./ \mathrm{m}^{3}\right)$, which is the infectious dose of SARS-COV-2; $t$ is the total exposure time that an occupant is 349 exposed in the air mixed with the infectious aerosol.

\section{Results and Discussion}

352 In this section, we present results for a clarinet and a singing performer. Additional results for all other 353 instruments and performers investigated in this study can be found in the supplemental information (SI). 


\subsection{Flow Characterization}

Figure 5 compares the maximum velocity measurements across the different methods used. Reasonable agreement can be seen despite the somewhat crude techniques and high uncertainty. These measurements were not designed to be comprehensive but were made to guide the plume measurements and initial CFD modeling. Detailed particle image velocity measurements are in progress.

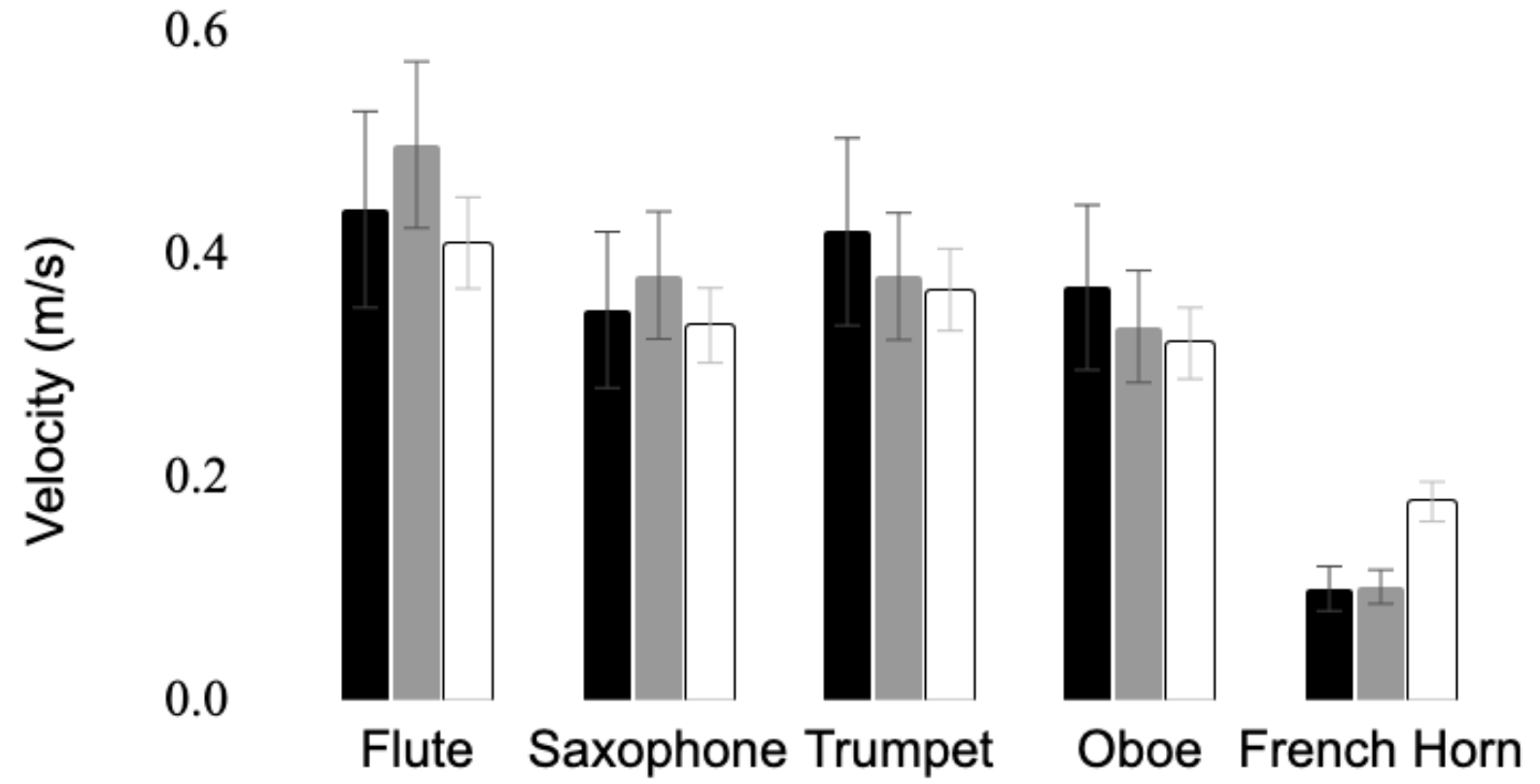

Figure 5. Maximum measured velocities and estimated uncertainties using hot wire anemometry (black), schlieren (gray), and laser sheet imaging (white).

We found that musicians and performers produce prominent jets. The jets are complex, unsteady, and highly three-dimensional as demonstrated by laser sheet images from the clarinet. Video (clarinet B flat major scale) of the side view as scales are played shows disorganized vortices although the flow is not truly turbulent, having a limited range of length scales. At a Reynolds number of 540 based on the bore diameter of $d_{o}=21 \mathrm{~mm}$ (measured at the junction between the bell and the lower joint) and an average speed of $0.4 \mathrm{~m} / \mathrm{s}$ the flow is transitional at most. Note that the air in the chamber was not stagnant during filming due to filters running and a small laser cooling fan. The video also shows that notes in the upper register overall produce jets of higher velocities out of the instrument's bell compared to most notes in the lower register. Anemometer measurements confirmed this, as well as showing that the lower registers have higher velocities out of the keyholes. The diameter of the jet from the clarinet was measured from the side view laser sheet videos at the plane of the bell. The initial jets ranged from 0.37 to $0.95 d_{o}$, depending on the note played. The jet diameter was dependent upon how many key holes were closed, and how fast the jet was traveling. 
378 Using a bell mask substantially decreased the speed and extent of the jet coming from the bell of the

379 instrument (videos: clarinet side w-wo mask, 1/4 speed recorded at $120 \mathrm{fps}$; clarinet front w-wo mask,

380 normal speed). The maximum horizontal velocity coming from the bell of the clarinet was $0.4 \mathrm{~m} / \mathrm{s}$

381 without a bell mask and $0.06 \mathrm{~m} / \mathrm{s}$ with a bell mask made out of two layers of 80 denier pantyhose. The

382 maximum jet length measured from the bell observed in the side view laser sheet from the clarinet was 15

$383 d_{o}(317.5 \mathrm{~mm})$ without a bell mask and $4 d_{o}(80 \mathrm{~mm})$ when a bell mask was utilized.

An even more dramatic reduction in jet speed and extent was seen in the case of the singer. The maximum horizontal velocity for singing was $0.78 \mathrm{~m} / \mathrm{s}$ without a mask and $0.01 \mathrm{~m} / \mathrm{s}$ with a mask. This finding is comparable to previous studies. A preprint study of 3 professional singers found a maximum singing velocity of $0.7 \mathrm{~m} / \mathrm{s}^{36}$ Giovanni et al. (2020) found that air velocity varied from $0.28 \mathrm{~m} / \mathrm{s}$ to $1.8 \mathrm{~m} / \mathrm{s}$ depending on the vocal exercise that was performed. ${ }^{37}$ The velocity for singing from this study was lower than what was found by Chao et al. (2009) for talking and coughing ( $3.9 \mathrm{~m} / \mathrm{s}$ and $11.7 \mathrm{~m} / \mathrm{s}$ respectively). ${ }^{38}$

391 Without a mask, the direction of the jets produced by the singer varies dramatically depending on the consonant or vowel sounds that are being spoken as the alphabet is recited, as seen in the schlieren imaging of Figure 5 (video: voice alphabet, 1/2 speed), played back at half speed. A jet interaction between mouth and nose can be seen during several letters, including J, L, N, U and Y. Again, although there is a prominent jet and the flow appears well-mixed, a Reynolds number estimate for the letter $\mathrm{F}$ is still only 260 , based on a diameter of $0.5 \mathrm{~cm}$ and a velocity of $0.8 \mathrm{~m} / \mathrm{s}$, indicating that viscous effects are important.

For singing, using a mask almost completely blocked air flow in the horizontal direction as shown in Figure 7 (video: singing w-wo mask). The schlieren imaging also indicated vertical air leaks at the top of the mask despite our attempts to properly fit it. The leakage flow was measured to be $0.3 \mathrm{~m} / \mathrm{s}$.

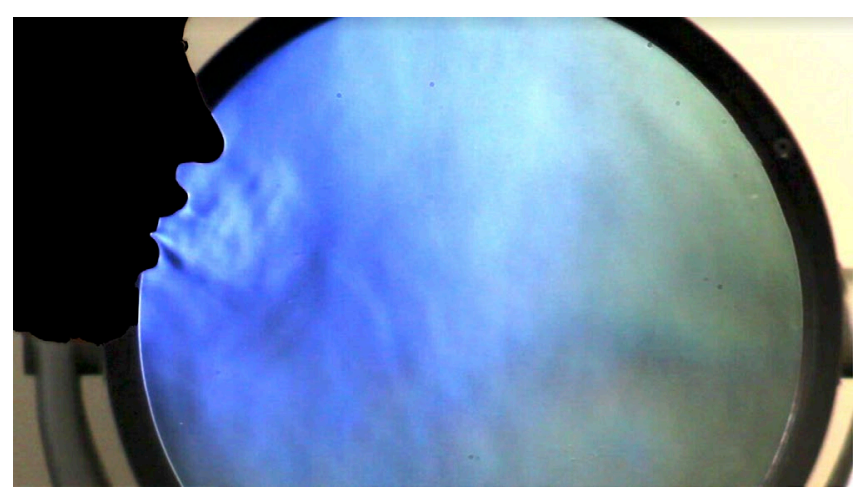




\section{3}

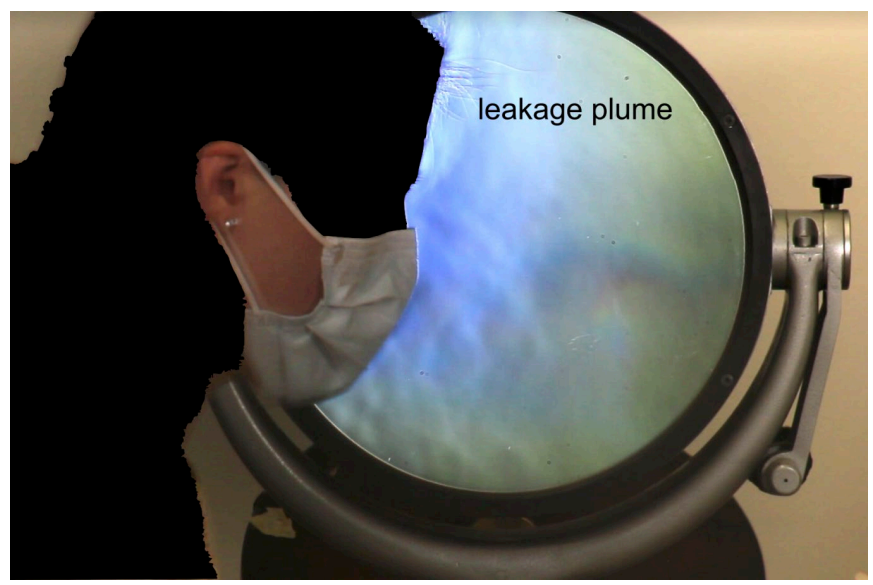

Figure 7: Observed leakage plume

Figure 8 summarizes jet velocity measurements with and without masks, showing that masks are effective at reducing potentially infective plumes. The maximum estimated error in our measurements is $0.1 \mathrm{~m} / \mathrm{s}$.

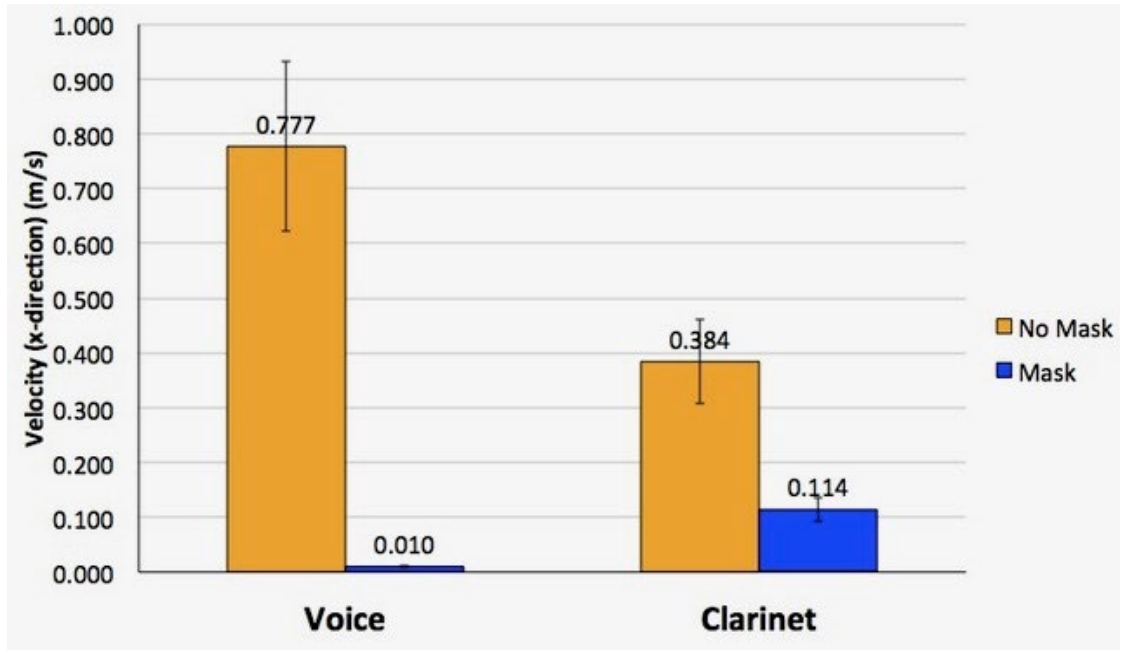

Figure 8: Average horizontal velocities (from schlieren imaging) are drastically reduced with mask.

\subsection{Aerosol Emissions from Singing and Playing Clarinet}

Particle concentrations measured in the plume as a function of time and activity are shown in Figure 9 and Figure 10. Noticeable spikes in aerosol production correspond with performance activity not utilizing mitigation measures. When masks were used by performers, the particle number concentration was comparable with background levels and levels measured while reading. The majority of aerosol number emitted from playing the clarinet and singing were particles with diameters less than $2.5 \mu \mathrm{m}$ in diameter. The clarinet player produced a higher number of sub-micron sized particles compared to the singer. There were noticeable spikes in the number of particles $<1 \mu \mathrm{m}$ in the same time periods for both the singer and 
421 clarinet player (Figure 9 and Figure 10). Liu et al (2020) mainly found SARS-CoV-2 in two size ranges,

$4220.25-1 \mu \mathrm{m}$, and $>2.5 \mu \mathrm{m} .{ }^{7}$ Particles less than $200 \mathrm{~nm}$ in diameter are not shown in the figure as they are 423 less likely to contain SARS-CoV-2.
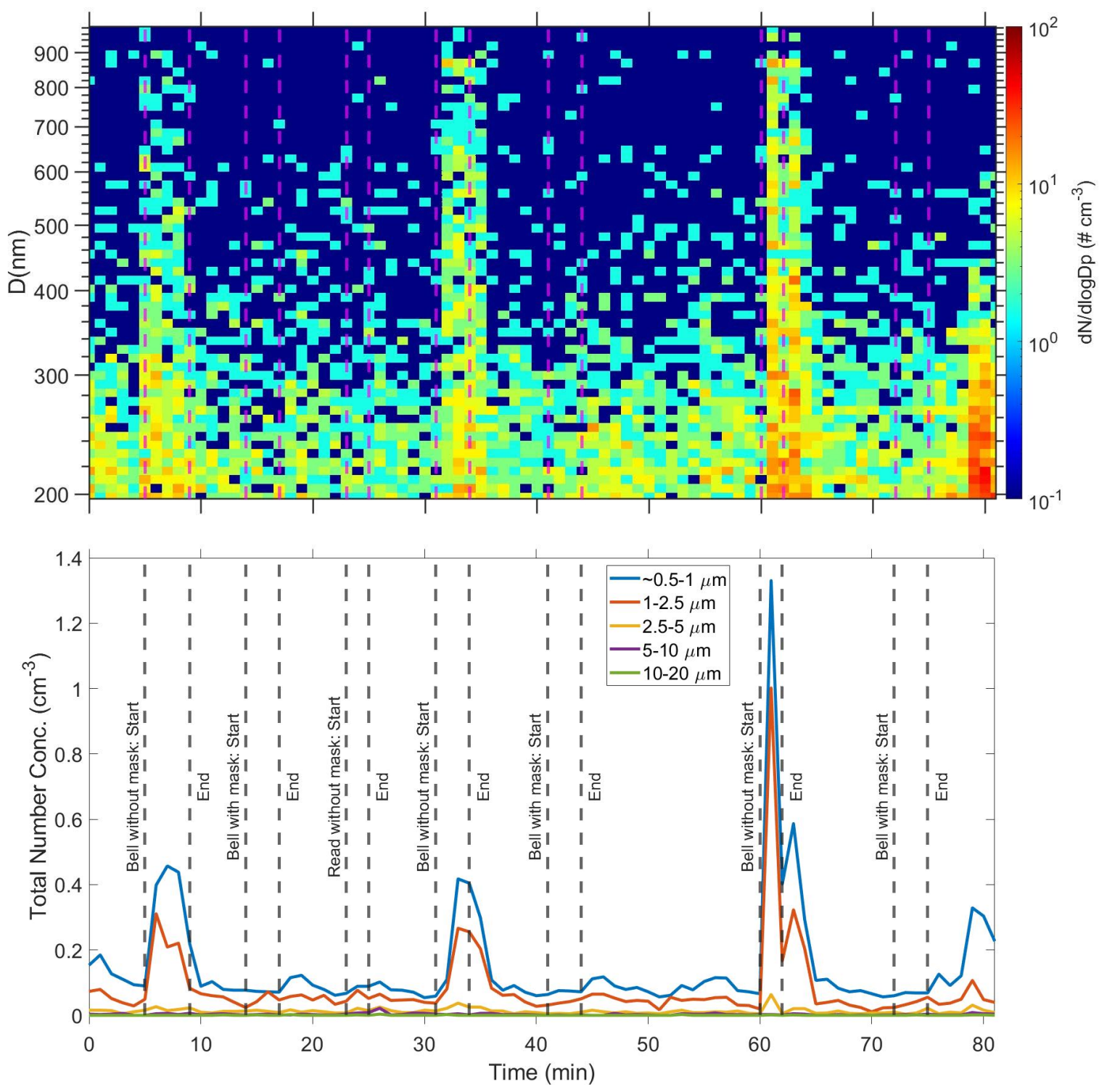

Figure 9. UHSAS size-resolved number concentration over time from $400 \mathrm{~nm}$ to $1000 \mathrm{~nm}$ for clarinet player (top). time of clarinet player (bottom) for particles in the ranges: 0.523-1 $\mu \mathrm{m}, 1-2.5 \mu \mathrm{m}, 2.5-5 \mu \mathrm{m}, 5-10 \mu \mathrm{m}$, and 10-20 $\mu m$. Sampling was done at the bell of the instrument. 

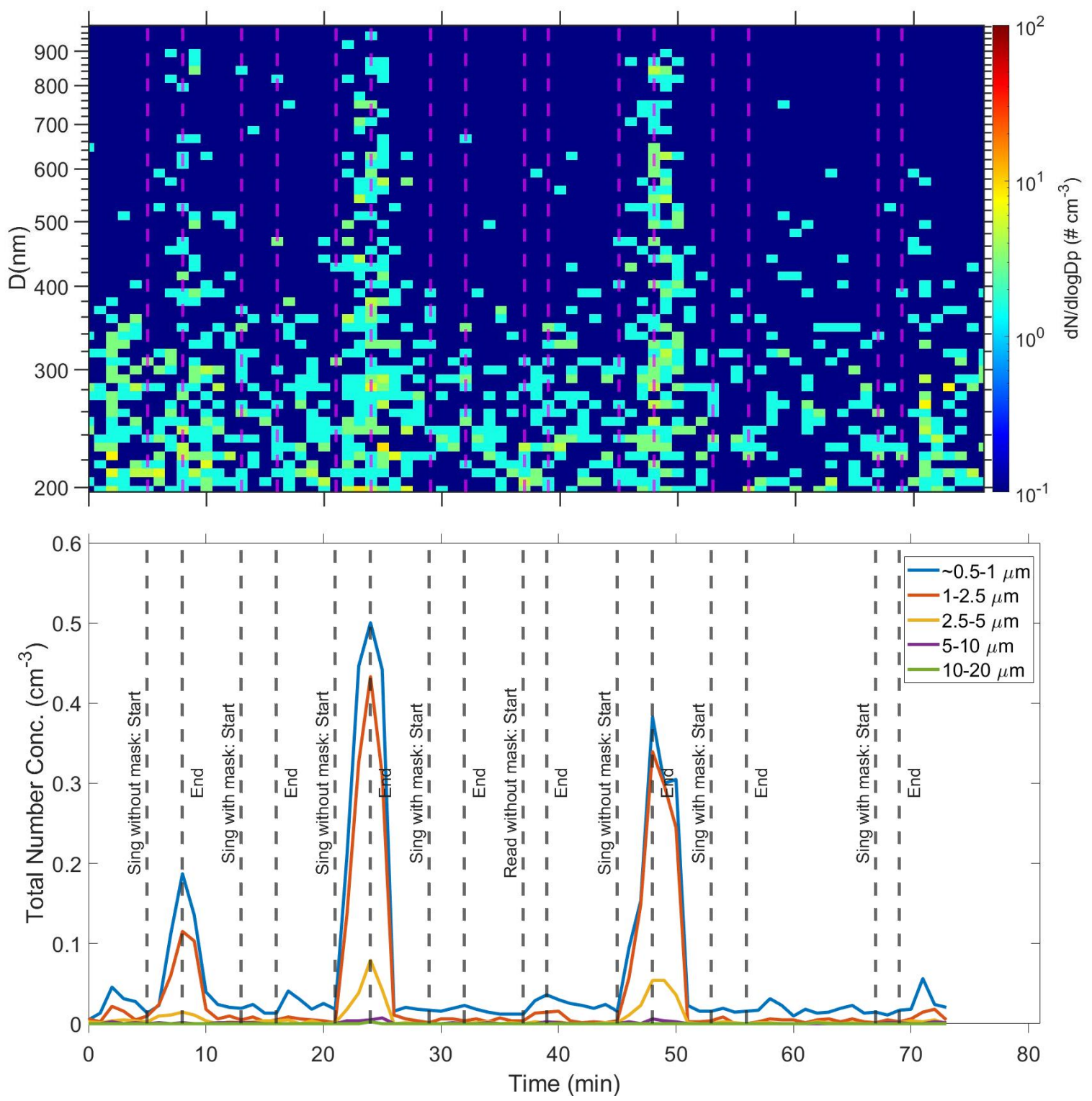

Figure 10. UHSAS size-resolved number concentration over time from $400 \mathrm{~nm}$ to $1000 \mathrm{~nm}$ for singer (top). The UHSAS particle concentrations were averaged over one minute. APS size-resolved number concentrations over time of singer (bottom) for particles in the ranges: 0.523 - $1 \mu \mathrm{m}, 1-2.5 \mu \mathrm{m}, 2.5-5 \mu \mathrm{m}, 5-10 \mu \mathrm{m}$, and 10-20 $\mu \mathrm{m}$. Sampling was done at the bell of the instrument.

438 Aerosol measurements from APS and UHSAS showed good agreement in their overlapping size range of $\sim 540-980 \mathrm{~nm}$ for total number concentration (Figure 11). 


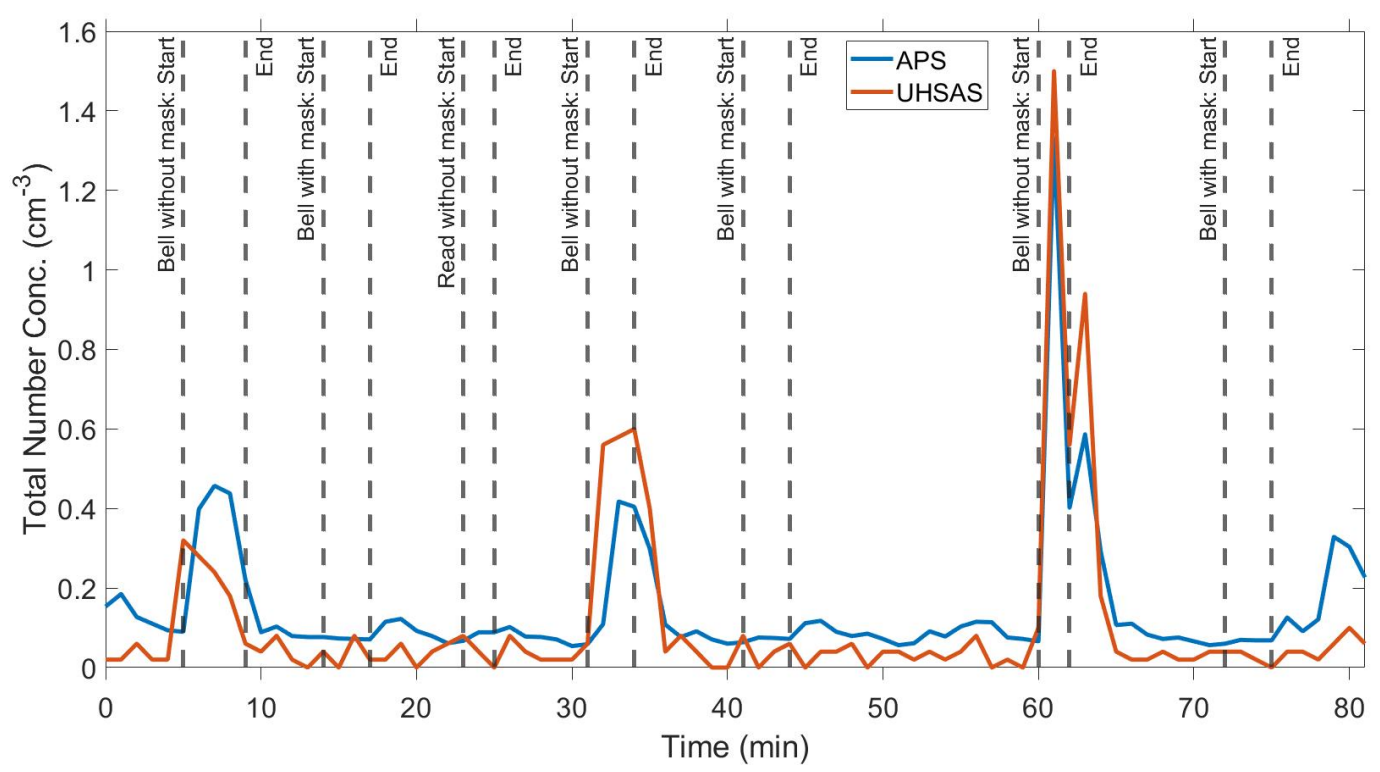

Figure 11. UHSAS and APS total number concentration for clarinet player for the overlapping size range common between the two instruments, $540-980 \mathrm{~nm}$. Time series of total concentrations played on the clarinet.

Exhaled aerosol concentrations measured in this study are comparable to prior literature, although we note that observed aerosol concentrations vary with the distance measured from the source, the loudness of the musician's playing, and the notes that the musician plays. In addition, various experimental designs were used across studies, which will lead to different aerosol losses. We also expect differences because of relative humidity and other environmental factors. A prior study utilizing an APS in which participants performed into a conical inlet found aerosol concentrations measured at the bell of the instrument ranging from $0.02-2.4$ particles $/ \mathrm{cm}^{3} .{ }^{20} \mathrm{He}$ et al. (2021) found that the clarinet generated approximately $\sim 0.1-$ 0.3 particles $/ \mathrm{cm}^{3} .^{20}$ The data from this study, however, showed that the aerosol concentration measured at the clarinet's bell to be upwards of 2.4 particles $/ \mathrm{cm}^{3}$, and comparable in magnitude to singing rather than normal speaking levels. McCarthy et al. (2021) found that the clarinet generated approximately 0.1 particles $/ \mathrm{cm}^{3}$ in the low note range, comparable to what they found for breathing, and approximately 2 particles $/ \mathrm{cm}^{3}$ in the high note range. ${ }^{39}$ The plume generated by playing the clarinet was highly directional, had high velocity, and dispersed quickly, which may lead to discrepancies between the studies. Our results that singing produced more aerosol compared to normal speaking levels are in agreement with Alsved et al. (2020). ${ }^{19}$

\subsection{Aerosol and $\mathrm{CO}_{2}$ Results}

$\mathrm{CO}_{2}$ can be used as a tracer for breathing and has a concentration of approximately $38,000 \mathrm{ppm}$ in breath. ${ }^{40}$ As the breath mixes into the ambient air, the $\mathrm{CO}_{2}$ concentration decreases, which happens with 
both time and distance from a breath plume event. We used $\mathrm{CO}_{2}$ as a tracer for the plume and calculated a particle- $\mathrm{CO}_{2}$ emission factor (EF), that is the total number concentration of particles of a certain size per ppm of $\mathrm{CO}_{2}$ increased above the background $\mathrm{CO}_{2}$ concentration. This ratio enabled us to normalize for the plume's dispersion into the ambient air for small particles. We estimate for the singer for particles $>$ $0.5 \mu \mathrm{m}$ an EF of $(1.1 \pm 0.2) \times 10^{-4} \mathrm{~cm}^{-3}$ per ppm $\mathrm{CO}_{2}$, and for the clarinet player $1.6 \times 10^{-4}\left( \pm 6.7 \times 10^{-5}\right) \mathrm{cm}^{-3}$ per ppm $\mathrm{CO}_{2}$ after removing one outlier point with a much higher ratio of $7.4 \times 10^{-4} \mathrm{~cm}^{-3}$ per ppm $\mathrm{CO}_{2}$. This outlier occurred at the beginning of the last test when the instrument was warm and wet. It is likely that there was resuspension of particles within the clarinet during this sample.

There was a steady rise in $\mathrm{CO}_{2}$ concentration of approximately $\Delta 300-500 \mathrm{ppm}$ in the room during the singer and clarinet player's performances as the participant respired. The distinct peaks of $\mathrm{CO}_{2}$ occurred during activities where the participant was close to the inlet and the plume was sampled, including when they were performing and speaking. There were noticeably large peaks in $\mathrm{CO}_{2}$ when each participant was asked to read the passage at normal speaking levels; however, there were not similar peaks in particle emissions during the same interval (Figure 12 and Figure 13). This is contrasted with the times when the participants played the clarinet or sang with no mask, in which there was a significant peak in both particle and $\mathrm{CO}_{2}$ emissions above background levels.

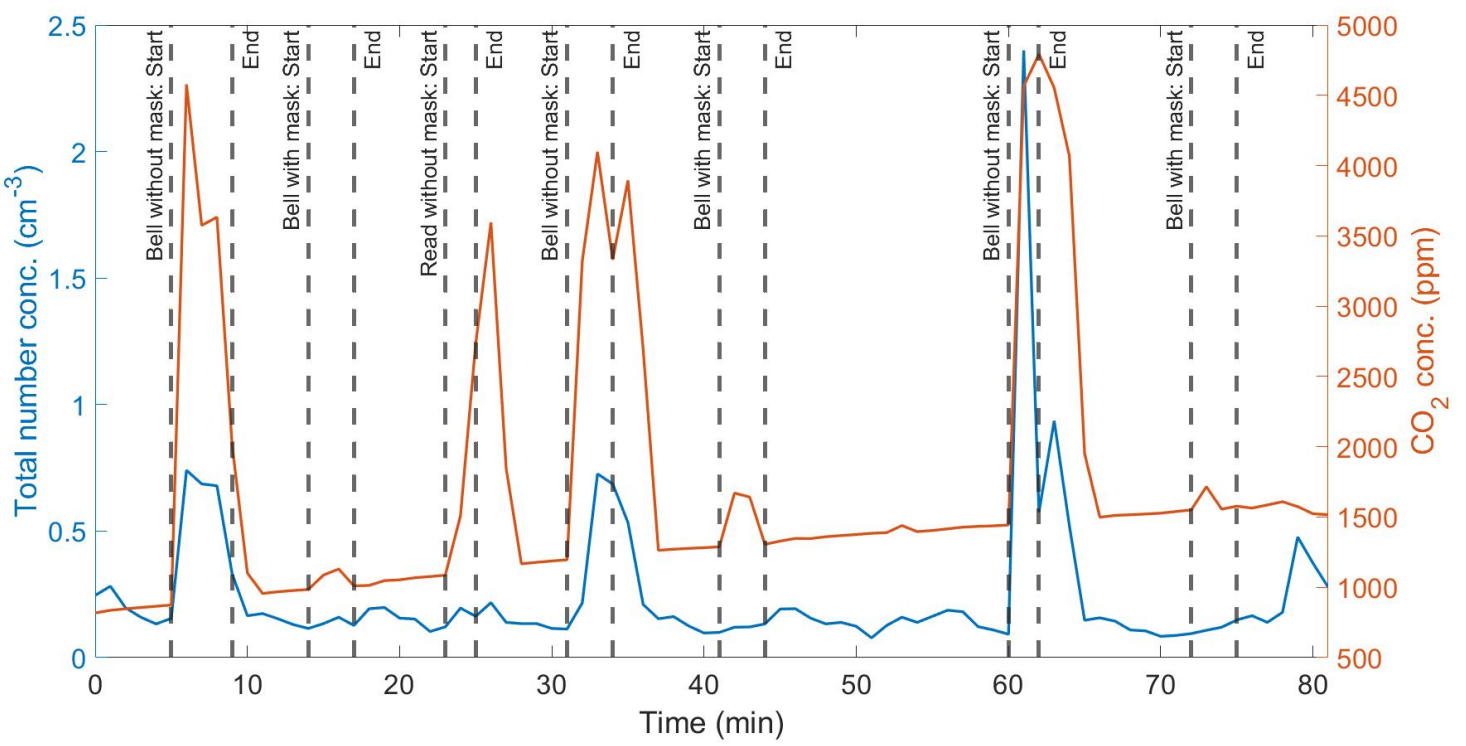

Figure 12. Total APS particle concentration over time (left axis), total $\mathrm{CO}_{2}$ concentration over time (right axis) for clarinet player. 


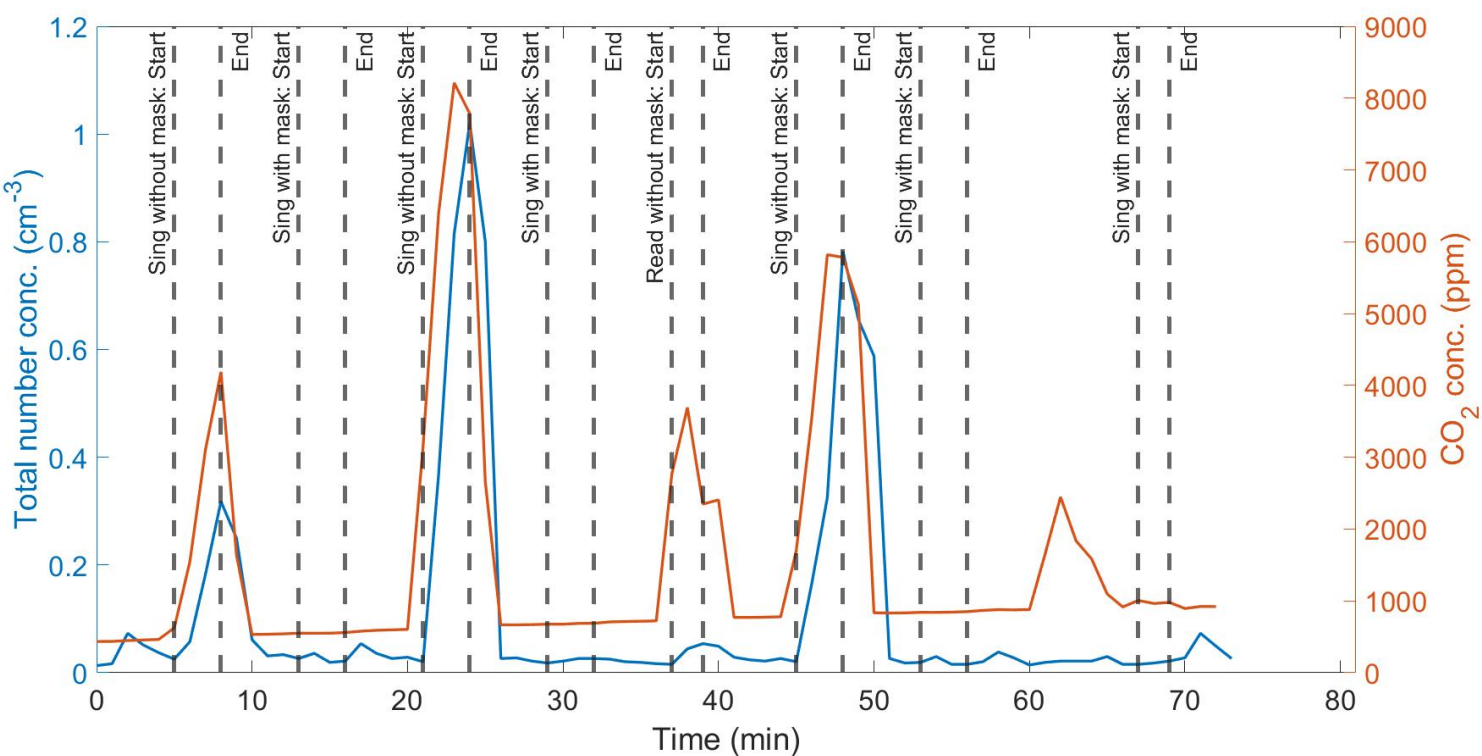

Figure 13. Total APS particle concentration over time (left axis), total $\mathrm{CO}_{2}$ concentration over time (right axis) for singer.

By measuring $\mathrm{CO}_{2}$ and aerosol simultaneously, we can compare plumes from a variety of humangenerated sources. For example, the large peak in $\mathrm{CO}_{2}$ without a correspondingly large peak in aerosol suggested that the emission rate of small particles when speaking at a normal level was low compared to singing or playing the clarinet (Figure 12). In addition, the ratio of total particle number concentration per ppm of $\mathrm{CO}_{2}$ was similar for singing and playing the clarinet, suggesting similar particle emission rates. Particle emission rate can be estimated from these ratios when the volumetric flow rate of playing the instruments is known.

We can also compare this EF to one estimated for breathing from the median number concentration of particles produced while breathing of $0.28 \mathrm{~cm}^{-3}(0.07,0.64$ interquartile range) measured by Gregson et al. $(2021)^{41}$ and the volume fraction added to exhaled breath during breathing of 0.038 estimated by Rudnick and Milton (2003). ${ }^{40}$ From the above values we get a median EF of $7.4 \times 10^{-6}\left(1.8 \times 10^{-6}, 1.7 \times 10^{-5}\right.$ interquartile range) $\mathrm{cm}^{-3}$ per ppm $\mathrm{CO}_{2}$, which two orders of magnitude lower than for singing and clarinet playing.

Combining $\mathrm{CO}_{2}$ concentrations with flow visualization is also a powerful tool. For example, aerosol number concentrations decreased significantly in front of the emission source when a mask was used but so too did the flow velocities and $\mathrm{CO}_{2}$ concentrations. A decrease in both $\mathrm{CO}_{2}$ concentration and flow velocity together showed that flow is became attenuated and well-mixed as it passed through the mask. 
The aerosol concentration measured in front of the mask compared to without it thus was not just due to the efficiency of the mask, for the mask also dispersed the plume's flow.

\subsection{Aerosol Emissions from Open Clarinet Keyhole}

509 The purpose of these experiments was to elucidate to what extent do particles leaking from keyholes contribute to emissions, especially when a surgical mask is used to cover the clarinet's bell (Figure 14).

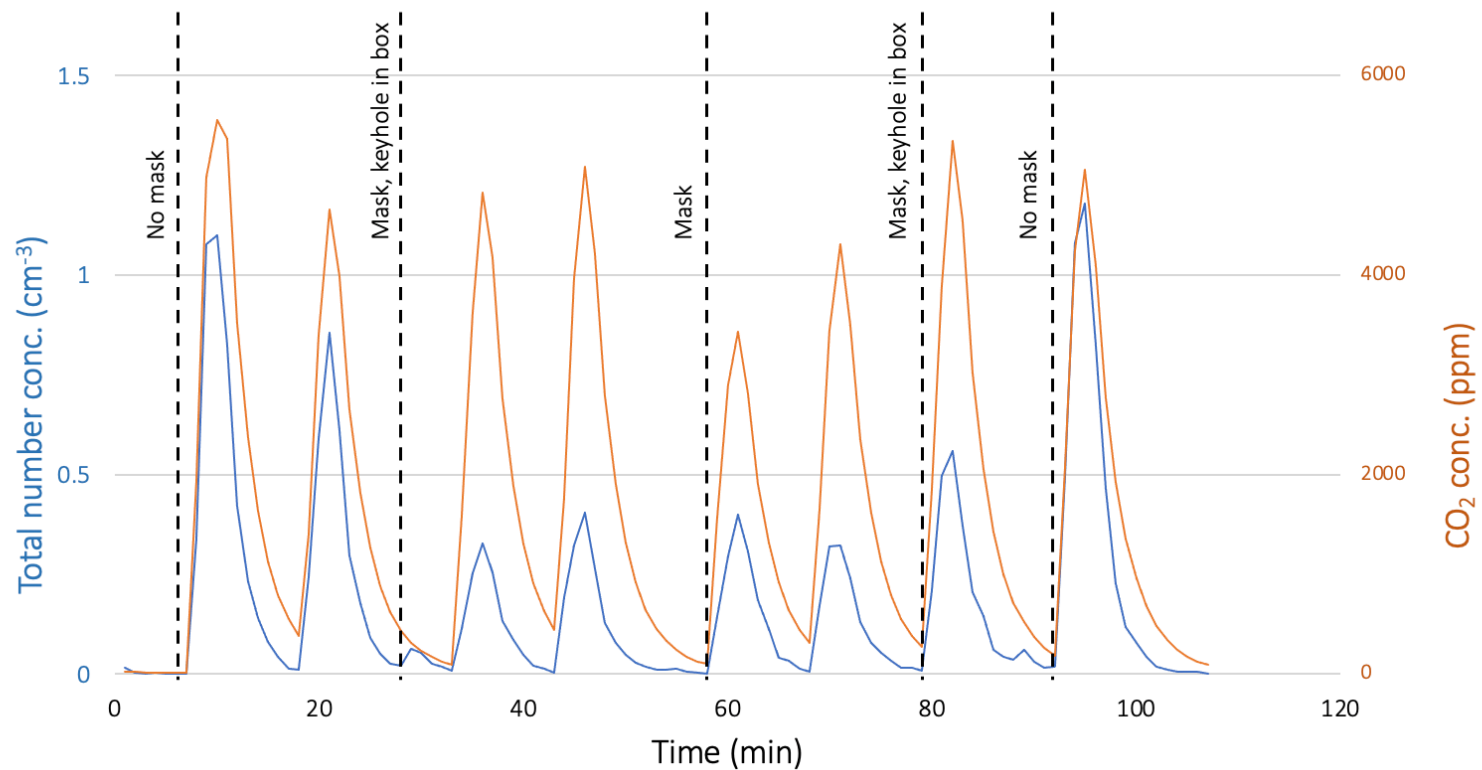

Figure 14. Clarinet played into a 53-L box, samples include the clarinet without a bell mask, the clarinet with a bell mask in which the open keyhole is not contained in the box, and the clarinet with a bell mask in which the open keyhole is contained in the box. Total number concentration of particles with diameters $>0.5 \mu$ m (left axis), $\mathrm{CO}_{2}$ concentration, ppm (right axis).

All the particles and $\mathrm{CO}_{2}$ in this enclosure are emitted by the musician or may have shed from the bell mask.

\begin{tabular}{|l|l|l|l|}
\hline & $\begin{array}{l}\text { Average Peak Total } \\
\text { Aerosol Concentration } \\
\left(\mathrm{cm}^{-3}\right)\end{array}$ & $\begin{array}{l}\text { Average Peak } \triangle \mathrm{CO}_{2} \\
\text { Concentration }(\mathrm{ppm})\end{array}$ & $\begin{array}{l}\text { Total Particle } \\
\text { Concentration }\left(\mathrm{cm}^{-3}\right) \\
\text { observed per ppm } \mathrm{CO}_{2}\end{array}$ \\
\hline No bell mask & $1.0(+/-0.17)$ & $4900(+/-630)$ & $2.2 \times 10^{-4}\left(+/-3.0 \times 10^{-5}\right)$ \\
\hline $\begin{array}{l}\text { Bell mask and open } \\
\text { Keyhole inside box }\end{array}$ & $0.42(+/-0.12)$ & $4800(+/-230)$ & $9.9 \times 10^{-5}\left(+/-2.9 \times 10^{-5}\right)$ \\
\hline $\begin{array}{l}\text { Bell mask and open } \\
\text { keyhole outside box }\end{array}$ & $0.36(+/-0.06)$ & $3700(+/-470)$ & $1.0 \times 10^{-4}\left(+/-1.6 \times 10^{-5}\right)$ \\
\hline
\end{tabular}


Table 2. Average peak total aerosol concentration of particles with diameters $>0.5 \mu \mathrm{m}$, average peak $\mathrm{CO}_{2}$ concentration, and total particle concentration $>0.5 \mu \mathrm{m}$ per ppm $\mathrm{CO}_{2}$ measured during experiments playing a clarinet into the box (+/- 1 Stdev).

A student t-test showed no significant difference in peak $\mathrm{CO}_{2}$ concentration when the bell was uncovered compared to when the bell was covered with a surgical mask and the open keyhole was contained in the box $(\mathrm{p}=0.84)$. However, there is a significant decrease in the peak change in $\mathrm{CO}_{2}$ concentration when the clarinet was played with the covered bell contained in the box without contribution of the open keyhole ( $\mathrm{p}$ $=0.044)$, indicating that respiratory emissions do exit the open keyhole.

The EF was calculated during the times when the clarinet was played and emitting particles. We conducted a student's t-test between each of the EF ratios. The EF is higher when the clarinet's bell is not covered compared to when it is covered with a surgical mask $(p<0.0001)$. There was no difference between the EF when the open keyhole was contained in the box compared to when it was not enclosed ( $p$ $=0.74)$. This keyhole is always slightly obstructed by a small key of cork and metal on which moisture collects over time, and so while $\mathrm{CO}_{2}$ escaped the keyhole, respiratory aerosol did not.

\section{The experiments with the clarinet being played into the box is an integrated signal of the plume-level} measurements with rapid dispersion into a small well-mixed volume. The concentration of $\mathrm{CO}_{2}$ in the box can be related to the amount of air the musician breathed into it. We found that the total aerosol concentration per ppm of $\mathrm{CO}_{2}$ when a bell mask was used was approximately half the total aerosol concentration per ppm of $\mathrm{CO}_{2}$ when no bell mask was used. This suggests that the aerosol emissions fell by approximately $50 \%$ for the same amount of respiration when a bell mask was used. Aerosol decreased more rapidly in the box compared to $\mathrm{CO}_{2}$ due to surface losses.

\subsection{Effect of Control Measures Across Different Types of Musical Performance}

Aerosol measurements taken near the instrument's bell or in front of a singer's mouth were decreased when a face or bell mask is worn (Figure 15). There was a large standard deviation for each of the noncontrol tests without masks due to variability in plumes of relatively low aerosol concentrations. 


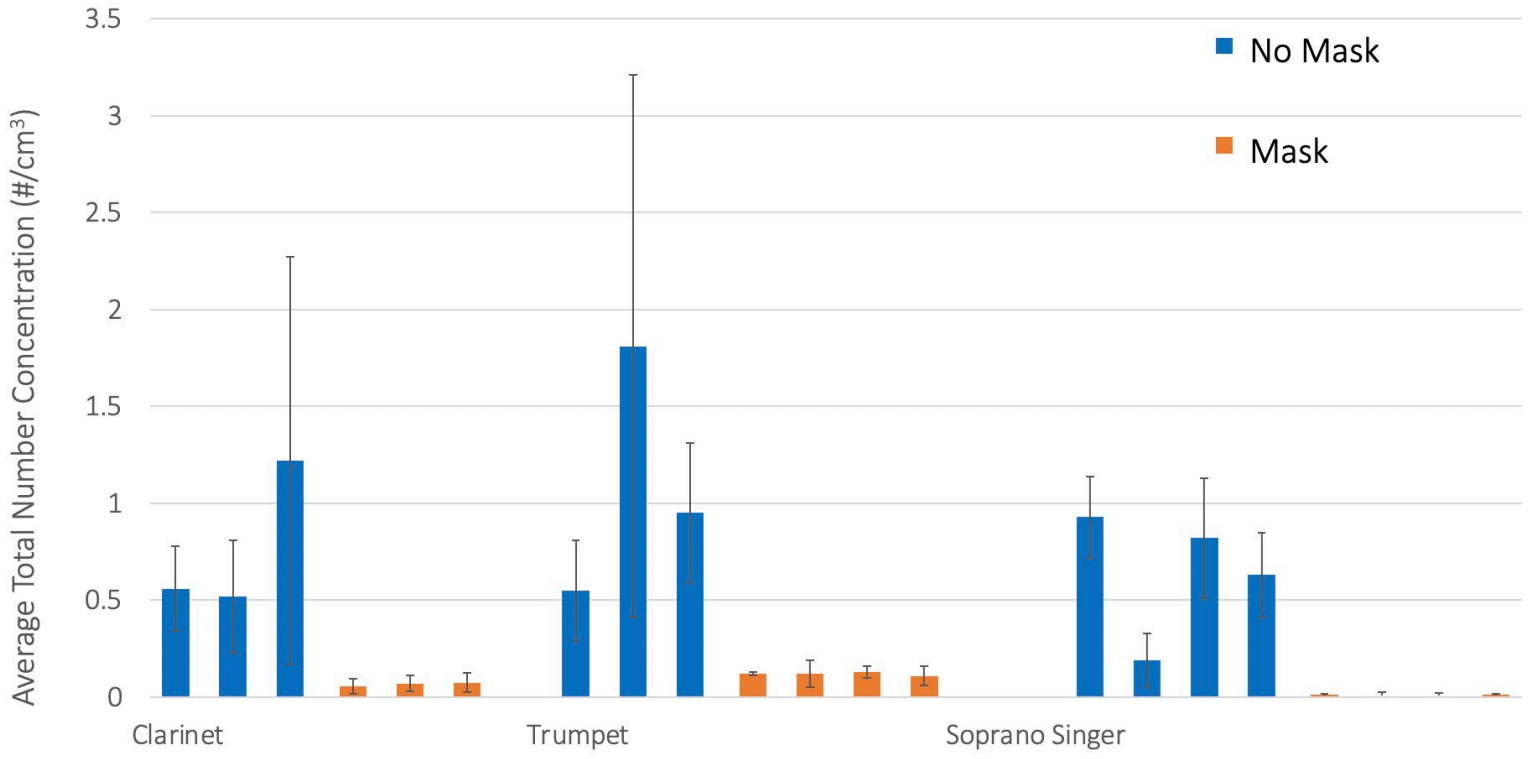

Figure 15. Average total particle number concentration ( $>0.5 \mathrm{~mm}$ in diameter) above background levels for clarinet, trumpet, and soprano singer with and without masks; surgical mask material, MERV-13 and spandex material, and surgical mask for clarinet, trumpet, and singer respectively. The error bars are $+/-1$ stdev. Each test was 4-5 minutes in length.

The plume measurements we collected should be understood in the context of the flow imaging. Because the plumes were highly directional, variable, had significant velocity, and dispersed rapidly, small differences in the participant's plume location impacted aerosol measurements, leading to high variability in the plume-level aerosol measurements. We measured $\mathrm{CO}_{2}$ to account for variability in plume-level measurements because the plumes disperse rapidly in time and space.

This study agrees with previous work that control measures such as masks when singing or speaking decreases the aerosol released into a room ${ }^{42-44}$ and that mask fit is important. ${ }^{45}$

We saw almost no fluctuations in $\mathrm{CO}_{2}$ concentrations in front of the face when a mask was worn compared to background increases in $\mathrm{CO}_{2}$, suggesting little breath from the participant was passing through the mask, but was instead passing out the top and sides between the face and the mask. Likewise, total aerosol concentration measured in front of the singer's mask were similar to background levels. As an exploratory measure to understand gaps in masks, we probed gaps around the surgical mask and saw high aerosol and $\mathrm{CO}_{2}$ concentrations at the gap between the mask and face near the singer's ear, a location not easily seen through schlieren imaging. This showed that aerosol easily escaped through gaps in a mask following streamlines about the face indicating which indicates the importance of fit. 


\subsection{Computational Fluid Dynamics}

573 The CFD results shown here are local air velocities, concentrations of emitted respiratory particles, and

574 risk of airborne transmission integrated over different time periods. These results provided the basis for an analysis of tradeoffs between risk to musicians and time spent in rehearsals. All the following results show a singer or clarinet player performing without masks.

\subsubsection{Velocity Distribution}

579 Figure 16 and Figure 17 present the spatial velocity distributions in the vertical section across the middle

580 plain of the musician body in indoor and outdoor environments, respectively. The air velocities are

581 similar in the wake of the musician's body in both indoor and outdoor environments. Additionally, the

582 outdoor airflow pattern was primarily driven by incoming wind, while the airflow pattern in the indoor

583 rehearsal room was driven by both the musician's activities and air supply into that confined space.

584 Figure 16 shows that the fluid field is relatively weak indoors and air movement was determined by the 585 interactions of ventilation airflow, thermal plume around the musician's body, and exhaled airflow from 586 the mouth or clarinet's bell opening.

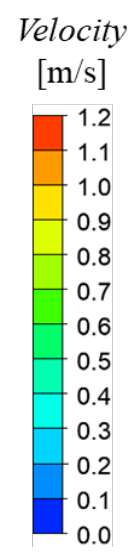

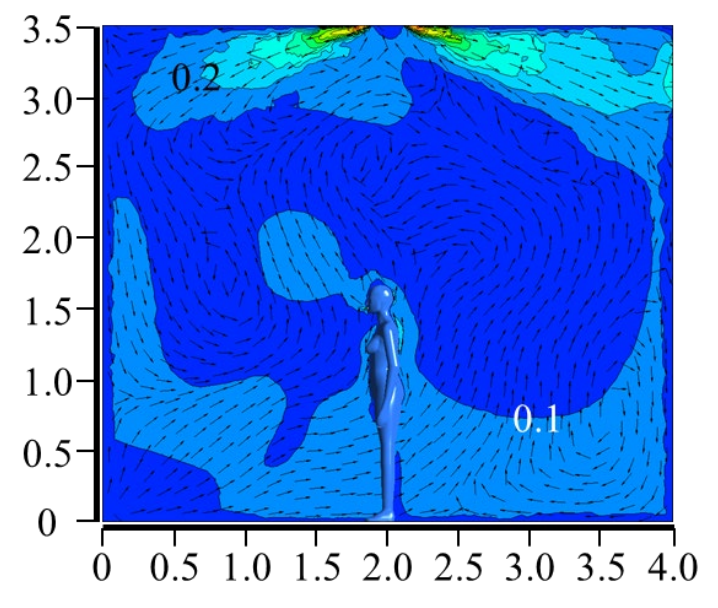

(a) Case 1

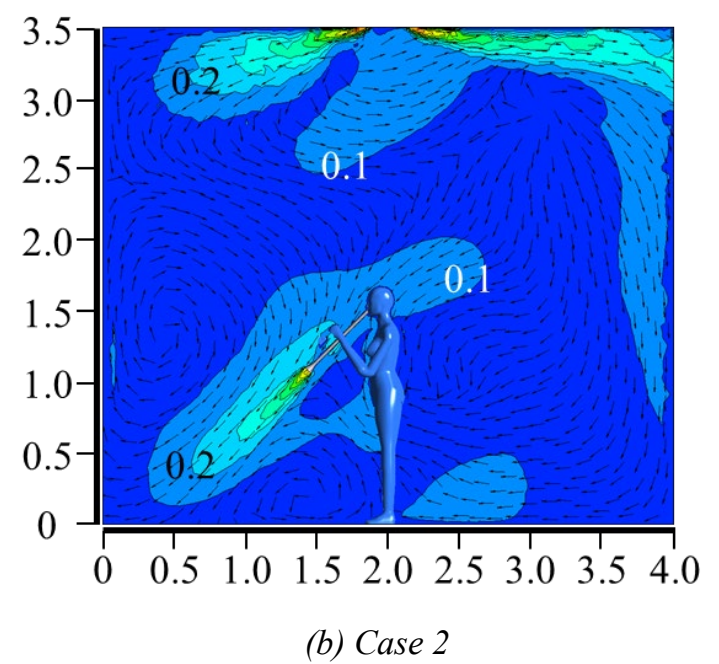

(b) Case 2

Figure 16. Flow field in the vertical section through the middle of musician's body in an indoor environment. X and $Y$ axes show distances in meters. 


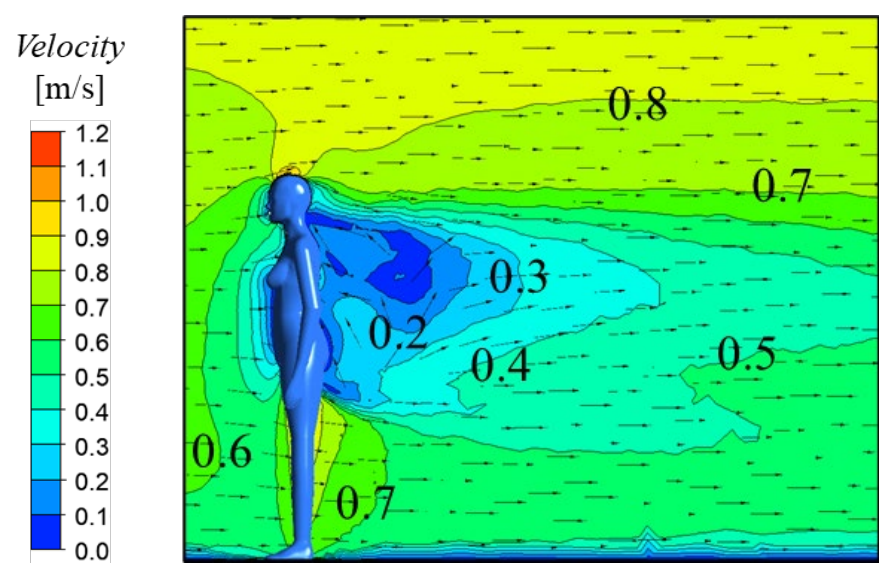

(a) Case 3

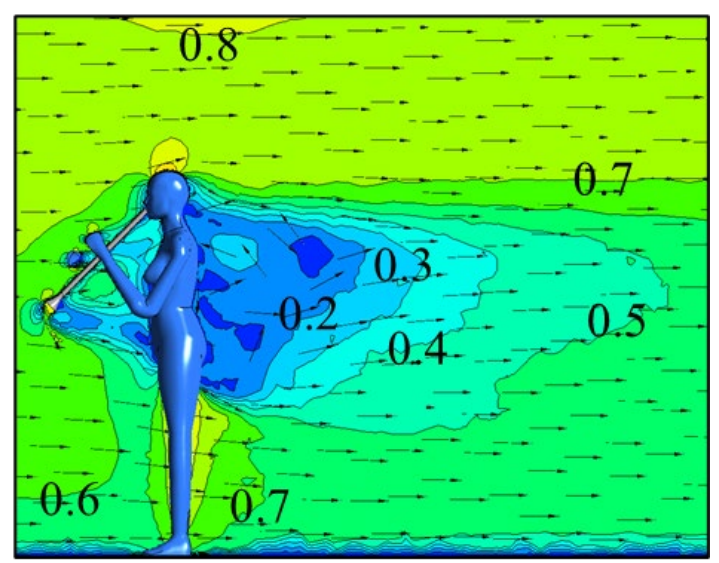

(b) Case 4

Figure 17. Flow field in the vertical section through the middle of the musician's body in an outdoor environment.

In Case 1 with a singer, air in the lower portion of the room was attracted and accelerated by the thermal plume around the musician's body, which was impacted by the exhaled airflow with a high momentum. The mixing of exhaled air with the thermal plume potentially enhanced the spread of exhaled aerosol at the height of mouth. In Case 2 with a clarinet player, the posture of playing the clarinet impedes the rising thermal plume. In addition, the expelled airflow from the bell's opening attracted the surrounding air and formed two air circulations above and below the expelled airflow, which may trap the expelled particles. The wind speed around the musician's body is higher outdoors compared to indoors. As a result, in both the cases, ambient wind demonstrates an overwhelming superiority in its interruption with exhaled airflow and thermal plumes around the musician's body, resulting in a similar flow field in the vicinity of the musician's body, especially the wake flow behind the body. It is notable that except in the area with wake flow, air is moved in the horizontal direction, with rare vertical mixing. Moreover, in the indoor environment, playing the clarinet weakens the thermal plume around the musician's body, resulting in a slightly higher velocity above the head.

\subsubsection{COVID-19 Quanta Concentration Distribution}

Figure 18 and Figure 19 present the spatial distributions of viral quanta concentrations in the vertical section across the middle of the musician's body in indoor and outdoor environments, respectively. In the indoor environment with a singer (Figure 18a), because exhaled air has a higher temperature than the ambient temperature, exhaled respiratory particles spread upwards due to buoyancy effect soon after being exhaled from the mouth. High concentrations of $>1$ quant $/ \mathrm{m}^{3}$ are limited in a narrow range close to the face. Because of the mixing of thermal plume and exhaled airflow, the quanta concentration is relatively higher throughout the middle portion of the room, including the breathing zones. In the indoor 
611 Due to the air circulation patterns, aerosol is spread through the whole room after the mixing of airflows.

612 The high concentrations of $>1$ quant $/ \mathrm{m}^{3}$ are only distributed in front of the bell opening.

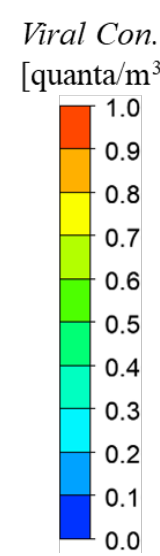

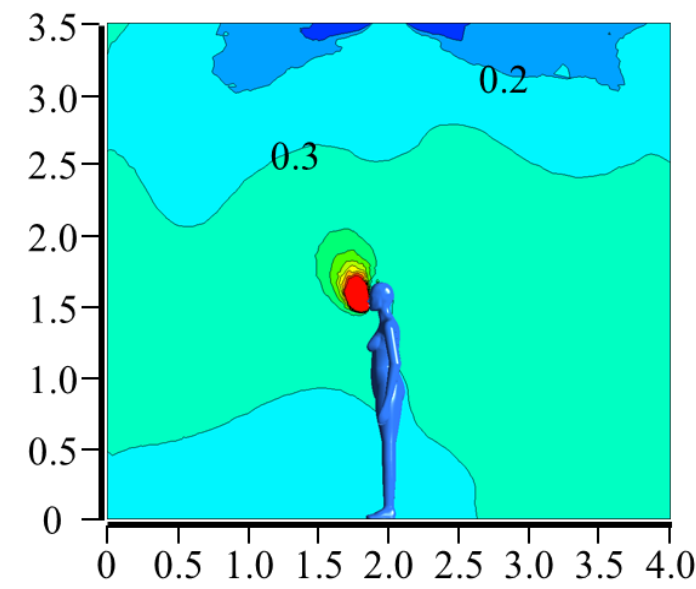

(a) Case 1

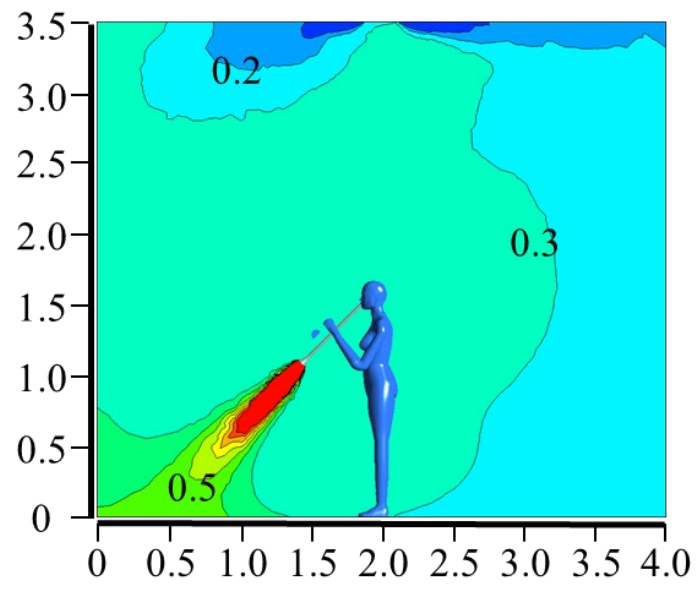

(b) Case 2

Figure 18. Quanta concentration distribution in the vertical section across the middle plain of the musician's body in the indoor environment. $X$ and $Y$ axes show distances in meters.

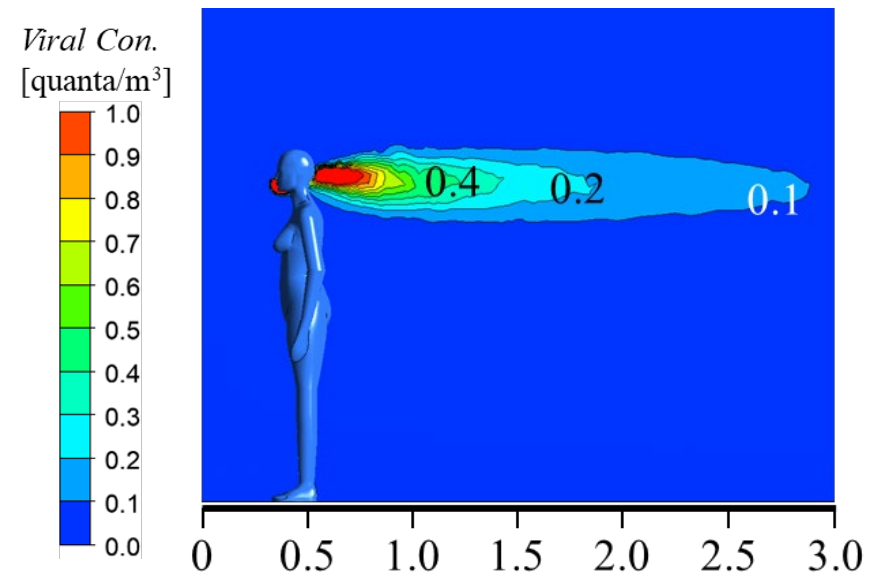

(a) Case 3

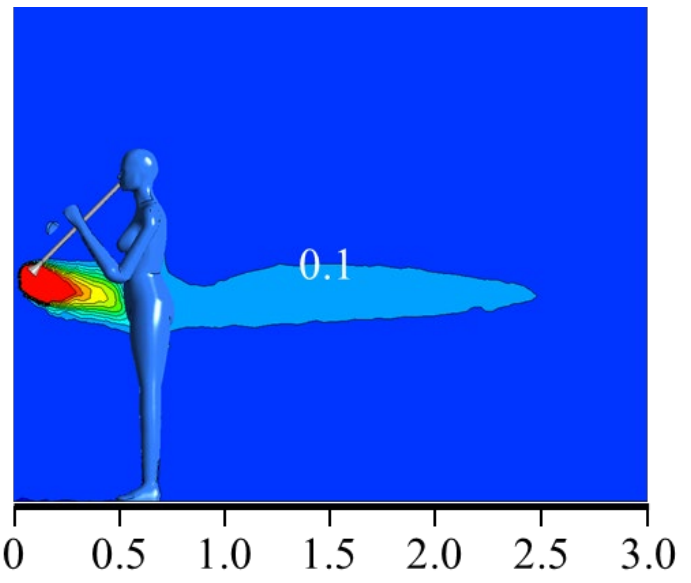

(b) Case 4

614 Figure 19. Quanta concentration distribution in the vertical section across the middle plain of the musician body in 615 the outdoor environment. $X$ and $Y$ axes show distances in meters.

617 As shown in Figure 19, in the outdoor environment, dominated by the ambient wind, the mixing of 618 aerosol around the musician's body is not as evident as indoors, especially in the vertical direction; and 619 the airborne particles are brought away soon after being expelled. In Case 3, the quanta concentrations of $620>0.1$ quant $/ \mathrm{m}^{3}$ only exist in a narrow area behind the head. In Case 4 , the high quanta concentrations of $>$ 
6210.2 quant $/ \mathrm{m}^{3}$ are restricted in a narrow area between the bell and musician body. Importantly, the quanta

622 concentration is $<0.1$ quant $/ \mathrm{m}^{3}$ at the height of mouth when playing clarinet outdoors.

\subsubsection{COVID-19 Infection Risk by the Wells-Riley Equation}

An infection risk assessment is the final step in the CFD analyses of music rehearsal events. Figure 20 across the middle plain of the performer's body, after 30- and 60- minute exposures, which are calculated by the quanta concentrations with Eq. (5), both indoors and outdoors, respectively. In the indoor environment, infection risk is mostly below $0.1(<10 \%$ chance of infection) except for a small area around the mouth in Case 1 with a singer or left lower corner in Case 2 with a clarinet player after a 30-minute

631 performance. However, the risk increases to above 0.1 across the section after a 60 -minute exposure in 632 both indoor cases.

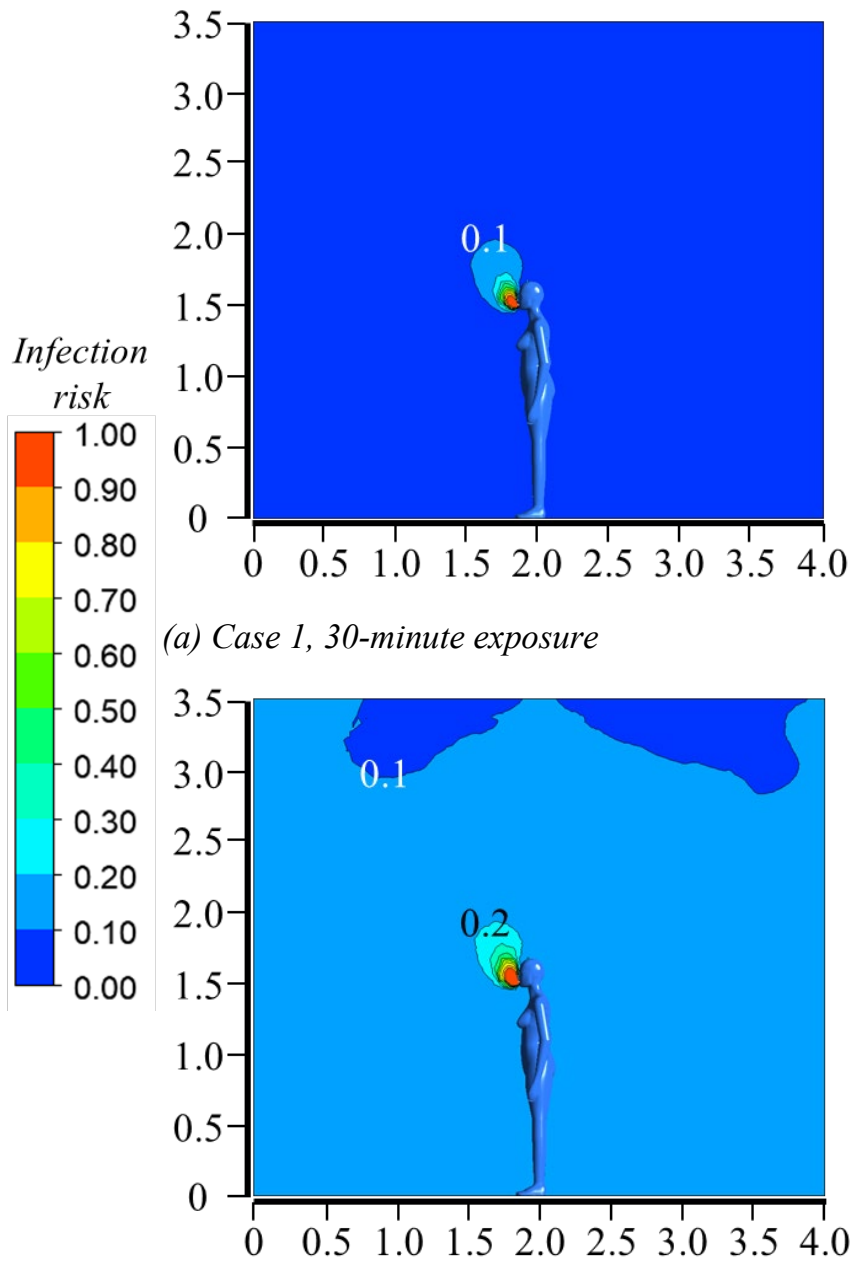

(c) Case 1, 60-minute exposure

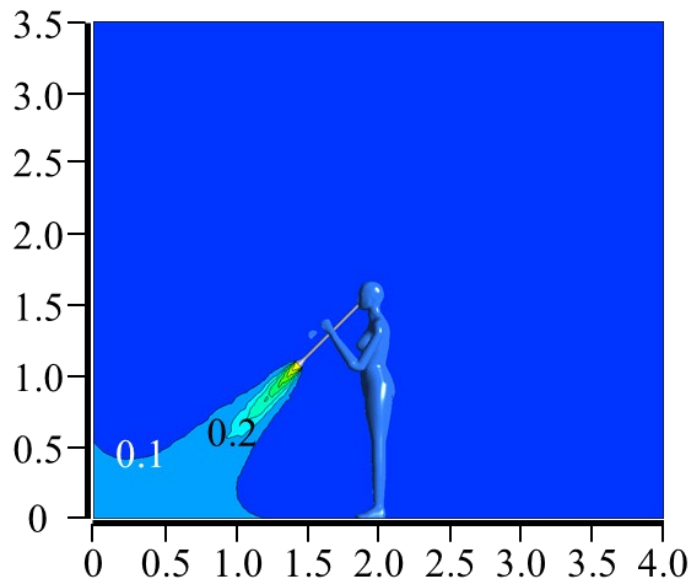

(b) Case 2, 30-minute exposure

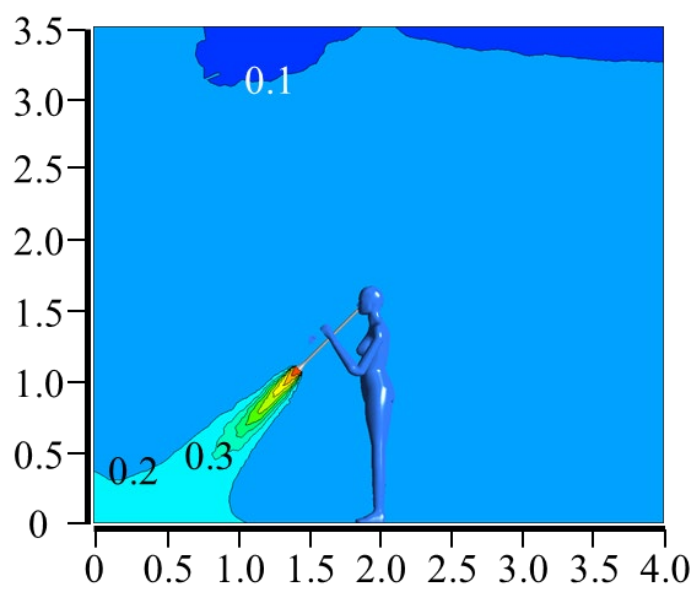

(d) Case 2, 60-minute exposure 
Figure 20. Quanta concentration distribution in the vertical section across the middle plain of the musician's body in the outdoor environment. $X$ and $Y$ axes show distances in meters.

636 Shown in Figure 21 (a) and (b), in the case with a singer, infection risk is only higher than 0.1 within 1.0 $637 \mathrm{~m}$ behind the musician body at the height of breathing zone after a 30-minute performance, but this range 638 is extended to $1.5 \mathrm{~m}$ behind the musician body after 60 -minutes of singing. In the case with a clarinet 639 player, infection risk is only higher than 0.1 between the clarinet's bell and musician body at the height of 640 the bell.

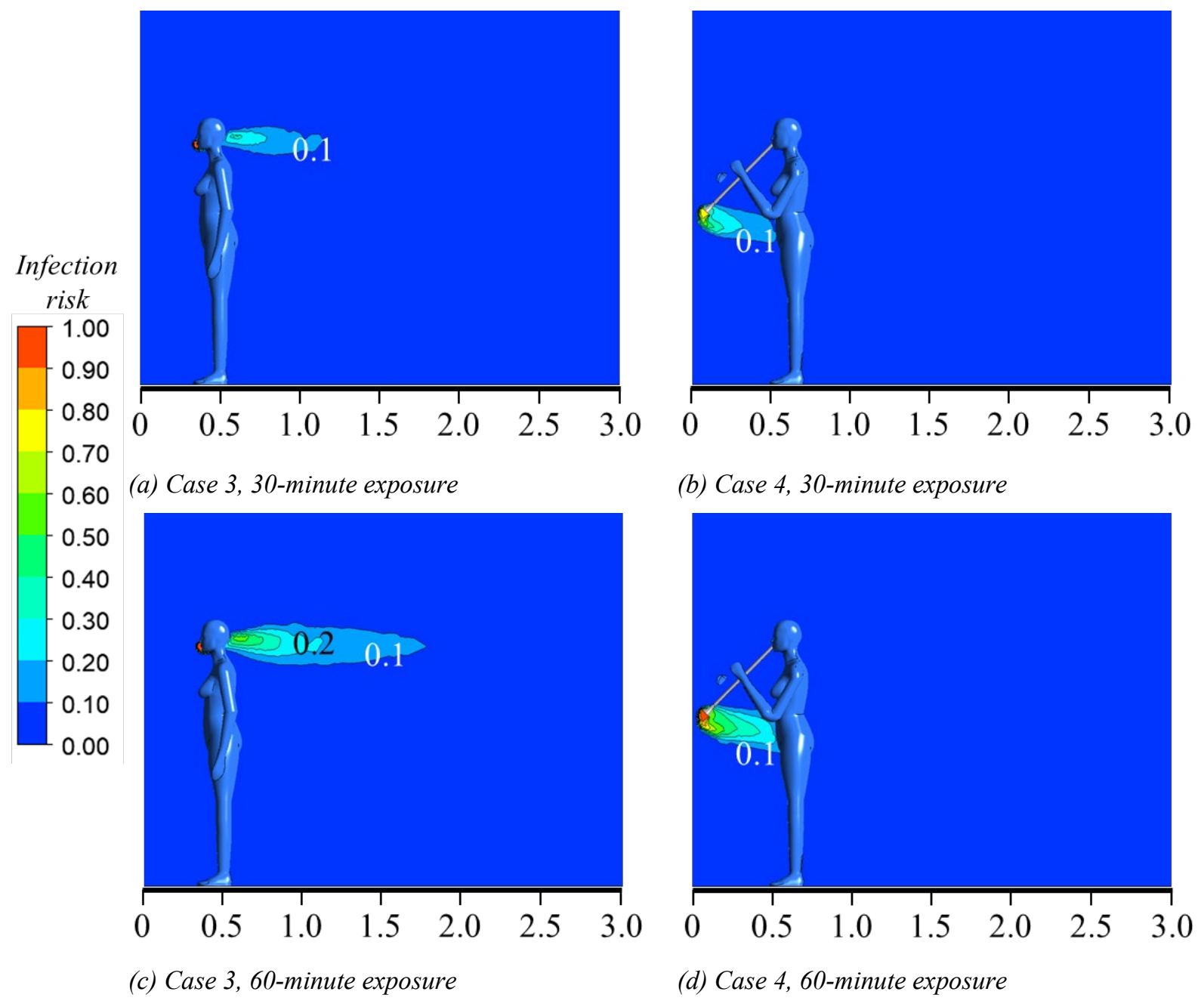

641 Figure 21. Infection risk distributions in the vertical section across the middle plain of the musician's body in the 642 outdoor environment. $X$ and $Y$ axes show distances in meters.

643 A previous study found that the influence of an air distribution system on exposure risk is generally the 644 same regardless of the duration of an event, after steady-state conditions have been achieved, although the 645 turbulence can contribute to some dynamic uncertainties. ${ }^{46}$ The steady-state CFD simulations in this study 
for the indoor environment show even abiding by the $1.83-\mathrm{m}(6-\mathrm{ft})$ social distance rule, the infection risk

647 continuously increases with the duration regardless of the distance to the singer or clarinet player. The

648 infection risk can be confined to under 0.1 with a 30-minute performance. Moreover, due to mixing from

649 the ventilation flow, the infection risk is similar no matter if the aerosol are comes from mouth or from

650 the clarinet's bell opening. When playing clarinet, the clarinet's angle has little influence on the resulted

651 infection risk for an audience staying 6-ft away from the player, under such a ventilation and air mixing

652 condition.

653

654 The outdoor environment was simulated at an ideal steady-state, without changes in wind speed and

655 direction. However, the simulation results show a difference between indoor and outdoor wind conditions,

656 as well as the differences in the spread of exhaled aerosol. In the outdoor environment, the ambient wind

657 shows an overwhelming effect on the spread of exhaled aerosol, and the particles are soon dispersed far

658 away. Therefore, the distribution of quanta concentration and infection risk will be qualitatively similar to

659 a general wind environment experienced outdoors. Moreover, the simulation represents a single wind

660 direction, so considering that the wind often changes its direction, the presented quanta concentrations

661 and infection risk will likely occur in a radius around the musician's body, rather than just behind the musician's body. For the case of the clarinet player, the quanta concentrations and infection risk may be slightly different due to the relative position to the musician's body, but it is conceivable that most likely, 664 they will be distributed at a height lower than the breathing zone. Infection risk is confined under 0.1 for the audience with a social distance of $1.83 \mathrm{~m}(6 \mathrm{ft})$ to the singer after a performance of 60 minutes and that playing clarinet may not cause remarkable infection risk under horizontal airflow.

667

\section{Conclusions}

While up to this date there have been no large outbreaks reported from playing musical wind instruments, there have been recorded outbreaks from choirs. ${ }^{12}$ Our study showed that performing with musical

671 instruments produced a greater number of airborne particles compared to normal speaking levels and

672 comparable levels to singing and theatre performances. Using masks greatly reduced the aerosol

673 concentration measured in front of the source. Plumes from talking, singing, and performing musical

674 instruments were highly three dimensional and vary considerably in time and space. The plumes decayed

675 rapidly and are highly unsteady, which lead to large variations in our plume-level measurements. In

676 addition, our flow characterization data show that when masks were used, plumes were shorter and plume

677 velocities decreased, which decreased the trajectory of highly concentrated jets of aerosol. 
679 Previous studies have included schlieren imaging, high-speed cameras to count particles, and aerosol

680 measurements from singers and various musical instruments. ${ }^{15,19,20}$ When sampling aerosol, other studies

681 have sampled via a cone connected to capture the aerosol from the source. ${ }^{19,20} \mathrm{We}$ instead first visualized

682 the airflow, and then measured aerosol in these airflows by probing the plume created by the performance

683 with multiple inlets positioned near each other, one inlet for particles $>0.5 \mu \mathrm{m}$ in diameter using an APS

684 and the other for particles $<1 \mu \mathrm{m}$ in diameter using a UHSAS and $\mathrm{CO}_{2}$ concentration using a Licor 7000.

685 Measuring $\mathrm{CO}_{2}$ enabled us to calculate an emission factor of the number of particles generated per ppm of

$686 \mathrm{CO}_{2}$, which can be used to compare aerosol generation rates across respiratory particle-generating

687 activities. Flow visualization and plume-level measurements both showed that masks attenuated flow of

688 the plumes generated when playing musical instruments and singing. Through testing the clarinet in a

689 small well-mixed box, we were able to integrate the signal of the plume measurement within a smaller

690 volume. We found that the surgical mask was effective at decreasing aerosol emissions from the clarinet

691 by approximately $50 \%$ and that the keyhole did not significantly contribute to aerosol generation.

692

693 CFD modeling showed differences between outdoor and indoor environments of singing and playing the

694 clarinet without masks. In an outdoor environment, ambient wind breaks the musician's thermal plume and expelled airflow and accelerates the dilution of aerosol. In an indoor environment, the musician's thermal plume and expelled airflow contribute to the spread of aerosol due to space confinement. In addition, the indoor walls force the formation of smaller eddies, and the consequent distribution of the particles. To minimize infection risk to musicians and audiences via aerosol, this study showed lowest risk with an exposure duration less than 30 minutes for indoor singing and clarinet playing, and an exposure duration less than 60 minutes for outdoor performance.

By combining flow visualization, plume-level measurements, and computational fluid dynamics, we were able to combine understanding from one method in order to inform another and develop a holistic understanding of the potential risks of musical performance.

\section{Supporting Information}

707 Recommendations for musicians based on our study findings and results for additional musical 708 instruments tested

\section{Acknowledgements}

710 We would like to thank all of the music organization supporters for their enthusiastic contributions to our 711 study. We would also like to thank the CU Boulder music program for helping us find participants, and to 
712 the many musicians who came to our lab and played for us in this study. We also thank our colleagues

713 across the world who are studying aerosol emissions from playing musical instruments and singing for

714 their valuable contributions to the design, execution and data interpretation of this study.

\section{Funding}

716

717

718

719

720

721

722

723

724

725

726

727

728

729

730

731

732

733

734

735

736

737

738

739

740

741

742

743

744

745

The author(s) disclosed receipt of the following financial support for the research, authorship, and/or publication of this article: This work was supported by an international coalition comprised of the following organizations: College Band Directors National Association (CBDNA), National Association of Music Merchants (NAMM), National Federation of State High School Associations (NFHS), D’Addario Foundation, Alabama Music Educators Association, American Choral Directors Association (ACDA), American School Band Directors Association (ASBDA), Arts Ed NJ, Athletes and the Arts, Association for Body Mapping Education, Association of Anglican Musicians (AAM), Association of Concert Bands, Barbershop Harmony Society, California Youth Symphony Association, Canadian Band Association (CBA), Choral Canada, Church Music Publishers Association (CMPA), College Orchestra Directors Association (CODA), Country Music Association Foundation, FargoMoorhead Orchestral Association, Florida Music Education Association (FMEA), French Musical Instrument Organisation (La Chambre Syndicale de la Facture Instrumentale, CSFI), Gala Choruses, Halifax Concert Band Society, Indiana Choral Directors Association, Indiana State School Music Association, Indianapolis Children's Choir, International Double Reed Society (IDRS), International Music Council, Kansas Bandmasters Association (KBA), Kappa Kappa Psi, Kentucky Music Educators Association (KMEA), Lakeville Area Community Band, League of American Orchestras, Lesbian \& Gay Band Association, Maine Music Educators Association (MMEA), Manitoba Band Association, Mid Penn Band Organization, Music Association of California Community Colleges (MACCC), Music for All, Music Learning Band Program, Music Teachers National Association (MTNA), Music Publishers Association, National Association for Music Education (NAfME), National Association of Teachers of Singing (NATS), National Collegiate Choral Organization (NCCO), National Guild for Community Arts Education, National Music Council of the US, National Speech and Debate Association (NSDA), New Horizons International Music Association (NHIMA), New York State Band Directors Association, New York State School Music Association (NYSSMA), North Carolina Music Educators Association, Nova Scotia Band Association, Oahu Band Directors Association, Ohio Foundation for Music Education (OFME), Ohio Music Education Association (OMEA), Opera America, Orcas Island Community Band, Orchestras Canada/Orchestras Canada, Organization of American Kodály Educators (OAKE), Performing Arts Medicine Association (PAMA), Phi Mu Alpha Sinfonia, Quadrant Research, Saskatchewan Band Association, Sigma Alpha Iota Philanthropies, Sing A Mile High International Children's Choral Festival, Slate Valley Singers, Songwriters Guild of America (SGA), South Dakota Bandmasters Association, 
South Dakota Music Education Association, Surrey Music Educators Association, Sweet Adeline's International (SAI), Tau Beta Sigma, Tennessee Music Education Association (TMEA), Texas Bandmasters Association, Texas Music Educators Association (TMEA), The College Music Society and The CMS Fund, The Main Street Singers, Inc (Main Street Children's Choir), The National Catholic Band Association, The Sinfonia Educational Foundation, The Voice Foundation, Virginia Music Educators Association, Voice and Speech Trainers Association (VASTA), Wisconsin School Music Association, Women Band Directors International (WBDI), World Association for Symphonic Bands and Ensembles (WASBE), Young Voices of Colorado, ACC Band Directors Association, Big 12 Band Directors Association, Big 10 Band Directors Association, PAC 12 Band Directors Association, SEC Band Directors Association, Clemson University Bands, Linn-Benton Community College Bands, UCLA Bands, Utah State University Bands

\section{References}

(1) Morawska, L.; Cao, J. Airborne Transmission of SARS-CoV-2: The World Should Face the Reality. Environ. Int. 2020, 139, 105730. https://doi.org/10.1016/j.envint.2020.105730.

(2) Chia, P.Y., Coleman, K.K., Tan, Y.K. Ong, S.W.X., Gum, M., Lau, S.K., Sutjipto, S., Lee, P.H., Son, T.T., Young, B.E., Milton, D.K., Gray, G.C., Schuster, S., Barkham, T., De, P.P., Vasoo, S., Chan, M., Ang, B.S.P., Tan, B.H., Leo, Y.S., Ng, O.-T., Wong, M.S.Y., Marimuthu, K., Detection of air and surface contamination by SARS-CoV-2 in hospital rooms of infected patients. Nat Commun 2020, 11, 2800. https://doi.org/10.1038/s41467-020-16670-2

(3) Ding, Z., Qian, H., Xu, B., Huang, Y., Miao, T., Yen, H-L., Xiao, S., Cui, L., Wu, X., Shao, W., Song, Y., Sha, L., Zhou, L., Xu, Y., Zhu, B., Li, Y. Toilets dominate environmental detection of severe acute respiratory syndrome coronavirus 2 in a hospital, Science of The Total Environment 2021. 753, 141710, https://doi.org/10.1016/j.scitotenv.2020.141710

(4) Guo, Y.; Wei, J.; Ou, C.; Liu, L.; Sadrizadeh, S.; Jin, T.; Tang, L.; Zhang, Y.; Li, Y. Deposition of Droplets from the Trachea or Bronchus in the Respiratory Tract during Exhalation: A Steady-State Numerical Investigation. Aerosol Sci. Technol. 2020, 54 (8), 869-879. https://doi.org/10.1080/02786826.2020.1772459.

(5) Jiang, Y.; Wang, H.; Chen, Y.; He, J.; Chen, L.; Liu, Y.; Hu, X.; Li, A.; Liu, S.; Zhang, P.; Zou, H.; Hua, S. Clinical Data on Hospital Environmental Hygiene Monitoring and Medical Staff Protection during the Coronavirus Disease 2019 Outbreak. 2020-03-02. medRxiv. https://doi.org/10.1101/2020.02.25.20028043. 2021-07-27.

(6) Lednicky, J. A.; Lauzardo, M.; Fan, Z. H.; Jutla, A.; Tilly, T. B.; Gangwar, M.; Usmani, M.; Shankar, S. N.; Mohamed, K.; Eiguren-Fernandez, A.; Stephenson, C. J.; Alam, M. M.; Elbadry, M. A.; Loeb, J. C.; Subramaniam, K.; Waltzek, T. B.; Cherabuddi, K.; Morris, J. G.; Wu, C.-Y. Viable SARS-CoV-2 in the Air of a Hospital Room with COVID-19 Patients. Int. J. Infect. Dis. 2020. 100, 476 - 482. https://doi.org/10.1016/j.ijid.2020.09.025.

(7) Liu, Y.; Ning, Z.; Chen, Y.; Guo, M.; Liu, Y.; Gali, N. K.; Sun, L.; Duan, Y.; Cai, J.; Westerdahl, D.; Liu, X.; Xu, K.; Ho, K.; Kan, H.; Fu, Q.; Lan, K. Aerodynamic Analysis of SARS-CoV-2 in Two Wuhan Hospitals. Nature 2020, 582, 557-560. https://doi.org/10.1038/s41586-020-2271-3.

(8) Ong, S. W. X.; Tan, Y. K.; Chia, P. Y.; Lee, T. H.; Ng, O. T.; Wong, M. S. Y.; Marimuthu, K. Air, Surface Environmental, and Personal Protective Equipment Contamination by Severe Acute Respiratory Syndrome Coronavirus 2 (SARS-CoV-2) From a Symptomatic Patient. JAMA 2020, 323 (16), 1610. https://doi.org/10.1001/jama.2020.3227. 
824

825

826

827

828

829

830

831

832

833

834

835

836

837

838

839

(9) Santarpia, J. L.; Rivera, D. N.; Herrera, V. L.; Morwitzer, M. J.; Creager, H. M.; Santarpia, G. W.; Crown, K. K.; Brett-Major, D. M.; Schnaubelt, E. R.; Broadhurst, M. J.; Lawler, J. V.; Reid, S. P.; Lowe, J. J. Aerosol and Surface Contamination of SARS-CoV-2 Observed in Quarantine and Isolation Care. Sci. Rep. 2020, 10 (1), 1-8. https://doi.org/10.1038/s41598-020-69286-3.

(10) Ma, J.; Qi, X.; Chen, H.; Li, X.; Zhang, Z.; Wang, H.; Sun, L.; Zhang, L.; Guo, J.; Morawska, L.; Grinshpun, S. A.; Biswas, P.; Flagan, R. C.; Yao, M. COVID-19 Patients in Earlier Stages Exhaled Millions of SARS-CoV-2 per Hour. Clin. Infect. Dis. 2021. 72, 652 - 654. https://doi.org/10.1093/cid/ciaa1283.

(11) Sia, S. F.; Yan, L.-M.; Chin, A. W. H.; Fung, K.; Choy, K.-T.; Wong, A. Y. L.; Kaewpreedee, P.; Perera, R. A. P. M.; Poon, L. L. M.; Nicholls, J. M.; Peiris, M.; Yen, H.-L. Pathogenesis and Transmission of SARS-CoV-2 in Golden Hamsters. Nature 2020, 583 (7818), 834-838. https://doi.org/10.1038/s41586-020-2342-5.

(12) Miller, S.L., Nazaroff, W.W., Jimenez, J.L., Boerstra, A., Buonanno, G., Dancer, S.J., Kurnitski, J., Marr, L.C., Morawska, L. and Noakes, C., 2021. Transmission of SARS-CoV-2 by inhalation of respiratory aerosol in the Skagit Valley Chorale superspreading event. Indoor Air. 2020. 31(2), 314323. https://doi.org/10.1111/ina.12751

(13) Gu, Y.; Lu, J.; Su, W.; Liu, Y.; Xie, C.; Yuan, J. Transmission of SARS-CoV-2 in the Karaoke Room: An Outbreak of COVID-19 in Guangzhou, China, 2020. J. Epidemiol. Glob. Health 2021. 11, 6-9. https://doi.org/10.2991/jegh.k.201007.001.

(14) Adam, D. C.; Wu, P.; Wong, J. Y.; Lau, E. H. Y.; Tsang, T. K.; Cauchemez, S.; Leung, G. M.; Cowling, B. J. Clustering and Superspreading Potential of SARS-CoV-2 Infections in Hong Kong. Nat. Med. 2020. 26, 1714 - 1719. https://doi.org/10.1038/s41591-020-1092-0.

(15) Lai, K.-M.; Bottomley, C.; McNerney, R. Propagation of Respiratory Aerosols by the Vuvuzela. PLoS ONE 2011, 6 (5), e20086. https://doi.org/10.1371/journal.pone.0020086.

(16) Loudon, R. G.; Roberts, M. R. Singing and the Dissemination of Tuberculosis. Am. Rev. Respir. Dis. 1968, 98, 297-300.

(17) Asadi, S.; Wexler, A. S.; Cappa, C. D.; Barreda, S.; Bouvier, N. M.; Ristenpart, W. D. Aerosol Emission and Superemission during Human Speech Increase with Voice Loudness. Sci. Rep. 2019. 9, 2348. https://doi.org/10.1038/s41598-019-38808-z.

(18) Johnson, G. R.; Morawska, L.; Ristovski, Z. D.; Hargreaves, M.; Mengersen, K.; Chao, C. Y. H.; Wan, M. P.; Li, Y.; Xie, X.; Katoshevski, D.; Corbett, S. Modality of Human Expired Aerosol Size Distributions. J. Aerosol Sci. 2011, 42 (12), 839-851. https://doi.org/10.1016/j.jaerosci.2011.07.009.

(19) Alsved, M.; Matamis, A.; Bohlin, R.; Richter, M.; Bengtsson, P.-E.; Fraenkel, C.-J.; Medstrand, P.; Löndahl, J. Exhaled Respiratory Particles during Singing and Talking. Aerosol Sci. Technol. 2020, 54 (11), 1245-1248. https://doi.org/10.1080/02786826.2020.1812502.

(20) He, R.; Gao, L.; Trifonov, M.; Hong, J. Aerosol Generation from Different Wind Instruments. $J$. Aerosol Sci. 2021, 151, 105669. https://doi.org/10.1016/j.jaerosci.2020.105669.

(21) Patel, R.; Connaghan, K.; Franco, D.; Edsall, E.; Forgit, D.; Olsen, L.; Ramage, L.; Tyler, E.; Russell, S. "The Caterpillar": A Novel Reading Passage for Assessment of Motor Speech Disorders. Am. J. Speech Lang. Pathol. 2013, 22 (1), 1-9. https://doi.org/10.1044/1058-0360(2012/11-0134).

(22) Volckens, J.; Peters, T. M. Counting and Particle Transmission Efficiency of the Aerodynamic Particle Sizer. J. Aerosol Sci. 2005, 36 (12), 1400-1408. https://doi.org/10.1016/j.jaerosci.2005.03.009.

(23) Wells, W.F. Airborne Contagion and Air Hygiene: An Ecological Study of Droplet Infections. J. Am. Med. Assoc. 1955. 159, 90-90. https://doi.org/10.1001/jama.1955.02960180092033

(24) RILEY, E. C.; MURPHY, G.; RILEY, R. L. AIRBORNE SPREAD OF MEASLES IN A SUBURBAN ELEMENTARY SCHOOL. Am. J. Epidemiol. 1978, 107 (5), 421-432. https://doi.org/10.1093/oxfordjournals.aje.a112560.

(25) Zhu, S.; Kato, S.; Yang, J.-H. Study on Transport Characteristics of Saliva Droplets Produced by Coughing in a Calm Indoor Environment. Build. Environ. 2006, 41 (12), 1691-1702. https://doi.org/10.1016/j.buildenv.2005.06.024. 
840

841

842

843

844

845

846

847

848

849

850

851

852

853

854

855

856

857

858

859

860

861

862

863

864

865

866

867

868

869

870

871

872

873

874

875

876

877

878

879

880

881

882

883

884

885

886

887

888

889

(26) Bouhuys, A.; Proctor, D. F.; Mead, J. Kinetic Aspects of Singing. J. Appl. Physiol. 1966, 21 (2), 483-496. https://doi.org/10.1152/jappl.1966.21.2.483.

(27) Blocken, B.; Stathopoulos, T.; Saathoff, P.; Wang, X. Numerical Evaluation of Pollutant Dispersion in the Built Environment: Comparisons between Models and Experiments. 4th Int. Symp. Comput. Wind Eng. CWE2006 2008, 96 (10), 1817-1831. https://doi.org/10.1016/j.jweia.2008.02.049.

(28) Defraeye, T.; Blocken, B.; Carmeliet, J. CFD Analysis of Convective Heat Transfer at the Surfaces of a Cube Immersed in a Turbulent Boundary Layer. Int. J. Heat Mass Transf. 2010, 53 (1), $297-$ 308. https://doi.org/10.1016/j.ijheatmasstransfer.2009.09.029.

(29) Liu, J.; Heidarinejad, M.; Pitchurov, G.; Zhang, L.; Srebric, J. An Extensive Comparison of Modified Zero-Equation, Standard k- $\varepsilon$, and LES Models in Predicting Urban Airflow. Sustain. Cities Soc. 2018, 40, 28-43. https://doi.org/10.1016/j.scs.2018.03.010.

(30) Blocken, B.; Defraeye, T.; Derome, D.; Carmeliet, J. High-Resolution CFD Simulations for Forced Convective Heat Transfer Coefficients at the Facade of a Low-Rise Building. Build. Environ. 2009, 44 (12), 2396-2412. https://doi.org/10.1016/j.buildenv.2009.04.004.

(31) Yakhot, V.; Orszag, S. A.; Thangam, S.; Gatski, T. B.; Speziale, C. G. Development of Turbulence Models for Shear Flows by a Double Expansion Technique. Phys. Fluids Fluid Dyn. 1992, 4 (7), 1510-1520. https://doi.org/10.1063/1.858424.

(32) Zhu, S.; Dalgo, D.; Srebric, J.; Kato, S. Cooling Efficiency of a Spot-Type Personalized AirConditioner. Build. Environ. 2017, 121, 35-48. https://doi.org/10.1016/j.buildenv.2017.05.007.

(33) Srebric, J.; Vukovic, V.; He, G.; Yang, X. CFD Boundary Conditions for Contaminant Dispersion, Heat Transfer and Airflow Simulations around Human Occupants in Indoor Environments. Indoor Air 2005 Model. Assess. Control Indoor Air Qual. 2008, 43 (3), 294-303. https://doi.org/10.1016/j.buildenv.2006.03.023.

(34) Chen, C.; Zhao, B. Some Questions on Dispersion of Human Exhaled Droplets in Ventilation Room: Answers from Numerical Investigation. Indoor Air 2010, 20 (2), 95-111. https://doi.org/10.1111/j.1600-0668.2009.00626.x.

(35) Dai, H.; Zhao, B. Association of the Infection Probability of COVID-19 with Ventilation Rates in Confined Spaces. Build. Simul. 2020, 13 (6), 1321-1327. https://doi.org/10.1007/s12273-020-07035.

(36) Richter, B.; Hipp, A.; Schubert, B.; Axt, M. R.; Stratmann, M.; Schmölder, C.; Spahn, C. From Classic to Rap: Airborne Transmission of Different Singing Styles, with Respect to Risk Assessment of a SARS-CoV-2 Infection. 2021-03-26. medRxiv. https://doi.org/10.1101/2021.03.25.21253694. 2021-07-27.

(37) Giovanni, A.; Radulesco, T.; Bouchet, G.; Mattei, A.; Révis, J.; Bogdanski, E.; Michel, J. Transmission of Droplet-Conveyed Infectious Agents Such as SARS-CoV-2 by Speech and Vocal Exercises during Speech Therapy: Preliminary Experiment Concerning Airflow Velocity. Eur. Arch. Otorhinolaryngol. 2021, 278 (5), 1687-1692. https://doi.org/10.1007/s00405-020-06200-7.

(38) Chao, C. Y. H.; Wan, M. P.; Morawska, L.; Johnson, G. R.; Ristovski, Z. D.; Hargreaves, M.; Mengersen, K.; Corbett, S.; Li, Y.; Xie, X.; Katoshevski, D. Characterization of Expiration Air Jets and Droplet Size Distributions Immediately at the Mouth Opening. J. Aerosol Sci. 2009, 40 (2), 122-133. https://doi.org/10.1016/j.jaerosci.2008.10.003.

(39) McCarthy, L. P.; Orton, C. M.; Watson, N. A.; Gregson, F. K. A.; Haddrell, A. E.; Browne, W. J.; Calder, J. D.; Costello, D.; Reid, J. P.; Shah, P. L.; Bzdek, B. R. Aerosol and Droplet Generation from Performing with Woodwind and Brass Instruments. Aerosol Sci. Technol. 2021. 1-11. https://doi.org/10.1080/02786826.2021.1947470.

(40) Rudnick, S. N.; Milton, D. K. Risk of Indoor Airborne Infection Transmission Estimated from Carbon Dioxide Concentration. Indoor Air 2003, 13 (3), 237-245. https://doi.org/10.1034/j.16000668.2003.00189.x.

(41) Gregson, F., Watson, N., Orton, C., Haddrell, A., McCarthy, L., Finnie, T., Gent, N., Donaldson, G., Shah, P., Calder, J., Bzdek, B., Costello, D., Reid., J. Comparing aerosol concentrations and particle 
size distributions generated by singing, speaking and breathing, Aerosol Science and Technology, 2021. 55, 681 - 691. https://doi.org/10.1080/02786826.2021.1883544

(42) Leung, N. H. L.; Chu, D. K. W.; Shiu, E. Y. C.; Chan, K.-H.; McDevitt, J. J.; Hau, B. J. P.; Yen, H.L.; Li, Y.; Ip, D. K. M.; Peiris, J. S. M.; Seto, W.-H.; Leung, G. M.; Milton, D. K.; Cowling, B. J. Respiratory Virus Shedding in Exhaled Breath and Efficacy of Face Masks. Nat. Med. 2020. 26, 676-680. https://doi.org/10.1038/s41591-020-0843-2.

(43) Milton, D. K.; Fabian, M. P.; Cowling, B. J.; Grantham, M. L.; McDevitt, J. J. Influenza Virus Aerosols in Human Exhaled Breath: Particle Size, Culturability, and Effect of Surgical Masks. PLoS Pathog. 2013, 9 (3), e1003205. https://doi.org/10.1371/journal.ppat.1003205.

(44) Wood, M. E.; Stockwell, R. E.; Johnson, G. R.; Ramsay, K. A.; Sherrard, L. J.; Jabbour, N.; Ballard, E.; O’Rourke, P.; Kidd, T. J.; Wainwright, C. E.; Knibbs, L. D.; Sly, P. D.; Morawska, L.; Bell, S. C. Face Masks and Cough Etiquette Reduce the Cough Aerosol Concentration of Pseudomonas Aeruginosa in People with Cystic Fibrosis. Am. J. Respir. Crit. Care Med. 2018, 197 (3), 348-355. https://doi.org/10.1164/rccm.201707-1457OC.

(45) Xu, C.; Wu, C.-Y.; Yao, M. Fluorescent Bioaerosol Particles Resulting from Human Occupancy with and Without Respirators. Aerosol Air Qual. Res. 2017, 17 (1), 198-208. https://doi.org/10.4209/aaqr.2016.09.0400.

(46) Ai, Z.; Hashimoto, K.; Melikov, A. K. Airborne Transmission between Room Occupants during Short-Term Events: Measurement and Evaluation. Indoor Air 2019, 29 (4), 563-576. https://doi.org/10.1111/ina.12557. 


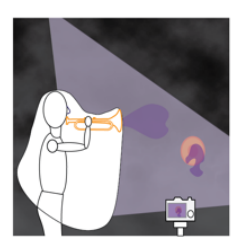

Flow Visualization $\longrightarrow$

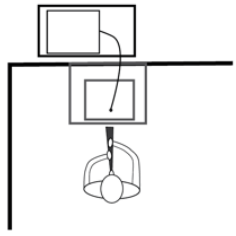

Plume

Measurements

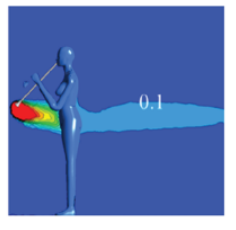

Computational

Fluid Dynamics

930

931 For Table of Contents Only 